\title{
Subunit Arrangement in GpsB, a Regulator of Cell Wall Biosynthesis
}

\author{
Robert M. Cleverley,, Jeanine Rismondo, Michael P. Lockhart-Cairns, ${ }^{3,4}$ Paulien T. Van Bentum, \\ Alexander J.F. Egan, Waldemar Vollmer, ${ }^{6}$ Sven Halbedel, ${ }^{2}$ Clair Baldock, \\ Eefjan Breukink, and Richard J. Lewis ${ }^{5}$
}

GpsB, a key regulator of cell division in Gram-positive bacteria, interacts with a key peptidoglycan synthase at the cell division septum, the penicillin binding protein PBP1 (a.k.a. PonA). Bacillus subtilis GpsB has been reported to interact with other components of the cell division machinery, including EzrA, MreC, and PrkC. In this study, we report an analysis of the arrangement of subunits in Listeria monocytogenes $\mathrm{GpsB}$ by small-angle X-ray scattering. The resulting model has an elongated shape with residues critical for interaction with PBP1 and the cell membrane clustered at one end of the molecule. Mutations that destabilize the hexameric assembly of the wild-type protein have a gpsB null phenotype, indicating that oligomerization is critical for the correct function of GpsB. We suggest a model in which a single GpsB hexamer can interact with multiple PBP1 molecules and can therefore influence the arrangement of PBP1 molecules within the cell division machinery, a dynamic multiprotein complex called the divisome, consistent with a role for GpsB in modulating the synthesis of the cell wall.

\section{Introduction}

B ACTERIAL CELL DIVISION has attracted increasing interest in recent years as a potential target of action for novel antibiotics in the battle against the rise of antimicrobial resistance to current therapies. ${ }^{1}$ Cell division is undertaken by the coordinated action of a dynamic assembly of proteins termed the divisome. ${ }^{2}$ A central component of the divisome is FtsZ, the bacterial homologue of tubulin, which drives division at midcell by forming the polymeric dynamic Z-ring that exerts a contractile force on the cytosolic face of the membrane during septal closure. ${ }^{3}$ Z-ring contraction is accompanied, on the opposite side of the membrane, by the remodeling of the essential peptidoglycan sacculus by penicillin binding proteins (PBPs) and peptidoglycan hydrolases, respectively. ${ }^{4}$ Division thus requires the coordination of processes on opposite faces of the cytoplasmic membrane. The membrane-associated proteins EzrA and GpsB appear to mediate this coordination in Gram-positive bacteria. ${ }^{5}$ FtsZ binds directly to the cytoplasmic domain of
EzrA, ${ }^{6,7}$ while bacterial two hybrid studies have revealed the interaction of both EzrA and GpsB with PBPs ${ }^{5,8,9}$; the interaction of GpsB with PBP1 (PonA), the major peptidoglycan synthase at the cell division septum in Bacillus subtilis, ${ }^{10}$ has also been observed in vitro by surface plasmon resonance and fluorescence polarization. ${ }^{11}$ The deletion of ezrA is lethal in Listeria monocytogenes ${ }^{12}$ and Streptococcus pneumoniae $e^{13-15}$ and is accompanied by the mislocalization of FtsZ and PBPs in both B. subtilis ${ }^{5}$ and Staphylococcus aureus. ${ }^{9}$ It is not clear whether $e z r A$ is essential in $S$. aureus, as opposing results have been obtained in different laboratories. ${ }^{8,9}$ Similarly, gps $B$ has been found to be essential in the pathogenic S. pneumoniae strain D39, where its depletion causes severe cell division defects, ${ }^{16}$ but not in other closely-related strains. ${ }^{13,14,17,18} \mathrm{GpsB}$ is important for virulence in L. monocytogenes, and here its knockout causes growth defects and increased susceptibility to lysis. ${ }^{11}$ Severe growth defects and perturbed localization of PBPs occur in B. subtilis upon the concurrent deletion of ezrA and $g p s B{ }^{5}$

\footnotetext{
${ }^{1}$ Institute for Cell and Molecular Biosciences, University of Newcastle, Newcastle upon Tyne, United Kingdom.

${ }^{2}$ FG11 Division of Enteropathogenic Bacteria and Legionella, Robert Koch Institute, Wernigerode, Germany.

${ }^{3}$ Diamond Light Source Ltd, Harwell Science \& Innovation Campus, Didcot, United Kingdom.

${ }^{4}$ Wellcome Trust Centre for Cell Matrix Research, Faculty of Life Sciences, University of Manchester, Manchester, United Kingdom.

${ }^{5}$ Membrane Biochemistry and Biophysics, Bijvoet Centre for Biomolecular Research, University of Utrecht, Utrecht, the Netherlands.

${ }^{6}$ Centre for Bacterial Cell Biology, Institute for Cell and Molecular Biosciences, University of Newcastle, Newcastle upon Tyne, United Kingdom.

(C) Robert M. Cleverley et al., 2016; Published by Mary Ann Liebert, Inc. This Open Access article is distributed under the terms of the Creative Commons Attribution Noncommercial License (http://creativecommons.org/licenses/by-nc/4.0/) which permits any noncommercial use, distribution, and reproduction in any medium, provided the original author(s) and the source are credited.
} 
The importance of GpsB in mediating the coordination of PBP activity with other divisome components is underlined by the interaction network in which GpsB participates. First, GpsB has been reported to interact with EzrA in two hybrid assays, although only unidirectionally, ${ }^{5}$ potentially providing an indirect link between FtsZ and PBPs, given that numerous in vitro and in vivo studies have shown that EzrA interacts with FtsZ (e.g., 6-9). Second, it has been reported that GpsB is phosphorylated in B. subtilis by PrkC, ${ }^{19}$ a eukaryotic-like membrane-embedded Ser/Thr kinase with an extracellular PASTA domain ${ }^{20}$ that binds peptidoglycan fragments. ${ }^{21}$ The relationship between GpsB and PrkC suggests that GpsB could be involved in transducing alterations in cell wall structure on the outside of the cell to the interior. Finally, a major portion of the GpsB sequence is homologous to the lipid binding domain of the DivIVA protein; the lipid binding domain promotes the localization of DivIVA to negatively curved lipid membranes, ${ }^{22}$ which is pivotal to DivIVA's role in promoting the assembly of the divisome at midcell. ${ }^{23}$ Whether GpsB regulates cell wall synthesis by similarly localizing to curved membranes remains to be clarified.

To help elucidate further the functional role of $\mathrm{GpsB}$, we recently solved crystal structures of its component domains from L. monocytogenes (LmGpsB) and B. subtilis (BsGpsB). ${ }^{11}$ GpsB proteins are typically approximately 100 amino acids in length and contain two domains, with the 65-70 amino acid $\mathrm{N}$ terminal domain $(\mathrm{N}-\mathrm{GpsB})$ resembling the lipid binding domain of DivIVA, a parallel coiled-coil dimer. ${ }^{23}$ The 20-25 amino acid C-terminal domain (C-GpsB) forms a parallel triple helical coiled-coil. ${ }^{11}$ While the $\mathrm{N}$ - and $\mathrm{C}$-terminal domains in isolation assemble into dimers and trimers, respectively, the full-length GpsB protein is a hexamer, ${ }^{11}$ which to date has been recalcitrant to successful crystallization. In this study, we present a study of the arrangement of subunits in $L m G p s B$ using small-angle X-ray scattering (SAXS) and a mutational analysis of candidate oligomer stabilizing residues. To understand the role of GpsB in cell division, we have also analyzed the enzymatic properties of PBP1 in the presence and absence of $B s G p s B$. In combination, these data are consistent with a model where GpsB serves to localize multiple copies of PBP1, a process that appears to be critical for efficient cell division.

\section{Materials and Methods}

\section{Bacterial strains and growth conditions}

All bacterial strains used in this study are listed in Table 1. L. monocytogenes strains were grown in brainheart infusion (BHI) broth or on BHI agar plates at $37^{\circ} \mathrm{C}$. When necessary, antibiotics and supplements were added to the growth media at concentrations of $50 \mu \mathrm{g} / \mathrm{ml}$ for kanamycin and $1 \mathrm{mM}$ for IPTG. The Escherichia coli strain TOP10 was used for all cloning procedures. ${ }^{24}$

\section{Construction of plasmids and strains}

The T88A, T88D, F91A, L94A, and F105A amino acid exchanges were introduced into L. monocytogenes gpsB, cloned previously into $\mathrm{pSH} 254$, by Quikchange mutagenesis $^{25}$ using the primer pairs JR290/JR291, JR291/JR293, JR311/JR312, JR313/JR314, and JR315/JR316, respectively (Table 2). The presence of the desired mutations was verified by DNA sequencing. The resulting plasmids are listed in
Table 1. Strains and Plasmids Used in This Study

Name Relevant characteristics $\quad \begin{gathered}\text { Source } \% \\ \text { reference }\end{gathered}$

Plasmids

pSH254 $\quad \mathrm{P}_{\text {help-lacO-gpsB lacI neo }}$

pJR133 $\quad \mathrm{P}_{\text {help }}$-lacO-gpsB T88A lacI neo

pJR134 $\quad \mathrm{P}_{\text {help-lacO-gpsB T88D lacI neo }}$

pSH433 $\quad \mathrm{P}_{\text {help-lacO-gpsB F91A lacI neo }}$

pSH434 $\quad \mathrm{P}_{\text {help-lacO-gpsB L94A lacI neo }}$

pSH435 $\quad \mathrm{P}_{\text {help-lacO-gpsB F105A lacI neo }}$

Listeria monocytogenes strains

EGD-e wild-type, serovar 1/2a strain

LMJR19 $\Delta$ gpsB (lmo1888)

LMS56 $\quad \Delta$ gpsB attB:: $\mathrm{P}_{\text {help }}$-lacO-gpsB lacI neo

LMJR161 $\Delta$ gpsB attB:: $\mathrm{P}_{\text {help }}$-lacO-gpsB T88A lacI neo

LMJR162 $\Delta$ gpsB attB:: $\mathrm{P}_{\text {help }}$-lacO-gpsB T88D lacI neo

LMS185 $\Delta$ gpsB attB:: $\mathrm{P}_{\text {help }}$-lacO-gpsB F91A lacI neo

LMS186 $\Delta$ gpsB attB $:: \mathrm{P}_{\text {help }}$-lacO-gpsB L94A lacI neo

LMS187 $\quad \Delta$ gpsB attB:: $\mathrm{P}_{\text {help }}$-lacO-gpsB F105A lacI neo

11

This work

This work

This work

This work

This work

54
11
11

pJR133 $\rightarrow$

LMJR19

pJR134 $\rightarrow$

LMJR19

$\mathrm{pSH} 433 \rightarrow$

LMJR19

$\mathrm{pSH} 434 \rightarrow$

LMJR19

$\mathrm{pSH} 435 \rightarrow$

LMJR19

${ }^{\mathrm{a}}$ The arrow $(\rightarrow)$ stands for a transformation event.

Table 1 and were introduced into L. monocytogenes EGD-e

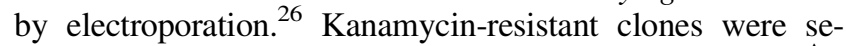
lected, and plasmid insertion at the $a t t B$ site of the tRNA ${ }^{\mathrm{Arg}}$ locus was verified by PCR.

To generate the plasmid for expressing C-LmGpsB, the open reading frame encoding $L$. monocytogenes $\mathrm{GpsB}$ residues 87-113 was PCR amplified from genomic DNA from strain EGD-e with primers RC87f and RC113f, which contain flanking NcoI and XhoI restriction sites, and cloned between the NcoI and XhoI sites of pMAT11, a modified form of pHAT4. ${ }^{27}$ The plasmids for expressing the full-length $L m \mathrm{GpsB}_{\mathrm{F} 91 \mathrm{~A}}, L m \mathrm{GpsB}_{\mathrm{F} 105 \mathrm{~A}}$ mutants and the double mutant $L m \mathrm{GpsB}_{\mathrm{F} 91 \mathrm{AF} 105 \mathrm{~A}}$ were prepared by Quikchange mutagenesis using primers RC91f, RC91r, RC105f, and RC105r; for the double mutant, two rounds of mutagenesis were used-the first round with primer pairs RC91f and RC91r and the second round with primer pairs RC105f and RC105r (Table 2).

Similarly, the full-length $B s \mathrm{GpsB}_{\mathrm{T} 75 \mathrm{E}}$ and $B s \mathrm{GpsB}_{\mathrm{T} 75 \mathrm{D}}$ mutants were prepared by Quikchange mutagenesis with primers RC75Ef and RC75Er, and RC75Df and RC75Dr, respectively; the plasmid for expressing full-length wildtype $B s \mathrm{GpsB}$ was used as a template for the Quikchange reaction to generate the $T 75 \mathrm{D}$ mutation. By contrast, for the T75E Quikchange reaction, the plasmid for expressing $B s \mathrm{GpsB}_{\mathrm{T} 75 \mathrm{D}}$ was used as a template. The resultant plasmids were sequenced to verify the successful introduction of the desired mutations and were subsequently used for the overproduction of the full-length GpsB variants by the same procedures as wild-type GpsB proteins. ${ }^{11}$

\section{Isolation of cellular proteins and Western blotting}

Cells were harvested by brief centrifugation in a table-top microfuge and washed with ZAP buffer $(10 \mathrm{mM}$ Tris- $\mathrm{HCl}$ 
Table 2. Oligonucleotides Used in This Study

\begin{tabular}{ll}
\hline Name & \\
\hline JR290 & \multicolumn{1}{c}{ Sequence $\left(5^{\prime} \rightarrow 3^{\prime}\right)$} \\
JR291 & GTTGGTTGCTCCAGCAGGTTGTG \\
JR292 & CTGCTGGAGCAACCAACTTTGATATC \\
JR293 & GTTGGTGTCTCCAGCAGGTTGTG \\
JR311 & CTGCTGGAGACACCAACTTTGATATTC \\
JR312 & GGAACAACCAACGCTGATATTCTAAAG \\
JR313 & CTTTAGAATATCAGCGTTGGTTGTTCC \\
JR314 & GATATTGCAAAGCGTCTTTCTAATTAG \\
JR315 & CTAAATTAGAAAGACGCTTTGCAATATC \\
JR316 & GAAAAACATGTTGCTGGAAATAAGCTG \\
RC91f & CAGCTTATTTCCAGCAACATGTTTTC \\
RC91r & CACAACCTGCTGGAACAACCAACGCTGATATTCTAAAGCGTCTTTC \\
RC105f & GAAAGACGCTTTAGAATATCAGCGTTGGTTGTTCCAGCAGGTTGTG \\
RC105r & CGTCTTTCTAATTTAGAAAAACATGTTGCTGGAAATAAGCTGGACGATAACG \\
RC75Ef & CGTTATCGTCCAGCTTATTTCCAGCAACATGTTTTTCTAAATTAGAAAGACG \\
RC75Er & CAGCCTGTGCAATCTAACGAAACAAACTTTGATATTTTAAAACG \\
RC75Df & CGTTTTAAAATATCAAAGTTTGTTTCGTTAGATTGCACAGGCTG \\
RC75Dr & CAGCCTGTGCAATCTAACGATACAAACTTTGATATTTTAAAACGGCTGTCTAACTTAG \\
RC87f & CTAAGTTAGACAGCCGTTTTAAAATATCAAAGTTTGTATCGTTAGATTGCACAGGCTG \\
RC113r & GCACAACCCATGGGAACAACCAACTTTGATATTCTAAAGCG \\
& CATAAGCTCGAGTTTCTCGCTCGTGGGGTTTAC
\end{tabular}

pH 7.5, $200 \mathrm{mM} \mathrm{NaCl}$ ). Cells were resuspended in $1 \mathrm{ml} \mathrm{ZAP}$ buffer containing $1 \mathrm{mM}$ PMSF and disrupted by sonication. The cell debris was removed by centrifugation, and the supernatant was used as the soluble protein extract. Protein samples were separated by SDS polyacrylamide gel electrophoresis and then transferred onto positively charged polyvinylidene fluoride (PVDF) membranes using a semidry transfer unit. GpsB and DivIVA were detected using polyclonal rabbit antisera raised against $L$. monocytogenes $\mathrm{GpsB}^{11}$ and $B$. subtilis DivIVA, ${ }^{28}$ respectively, with anti-rabbit immunoglobulin $\mathrm{G}$ conjugated to horseradish peroxidase as the secondary antibody. The ECL chemiluminescence detection system (Thermo Scientific) was then used for detection of the peroxidase conjugates on the PVDF membranes in a chemiluminescence imager (Vilber Lourmat).

\section{Protein purification}

PBP1 and GpsB proteins were purified as described previously. ${ }^{11} \mathrm{C}-L m \mathrm{GpsB}$ proteins were expressed as fusion proteins with $\mathrm{N}$-terminal $\mathrm{His}_{6^{-}}$and MBP-tags; the protocols for expression and purification of the fusion protein by Ni-NTA chromatography were as described previously for $\mathrm{C}-B s \mathrm{GpsB} .{ }^{11}$ Following Ni-NTA chromatography, the fusion protein was cleaved with TEV protease (ratio of fusion protein:TEV 50:1 by mass) overnight at $4^{\circ} \mathrm{C}$ while simultaneously dialyzing into a buffer of $50 \mathrm{mM}$ Tris- $\mathrm{HCl} \mathrm{pH} 8.0,300 \mathrm{mM}$ $\mathrm{NaCl}$ using a $2 \mathrm{kDa}$ molecular weight cutoff dialysis membrane. The dialysate was passed back over a $5 \mathrm{ml}$ Ni-NTA cartridge (Qiagen) to separate TEV protease, C-LmGpsB released by cleavage from the fusion protein and residual uncleaved $\mathrm{His}_{6}-\mathrm{MBP}-\mathrm{C}-\mathrm{L} m \mathrm{GpsB}$. The flow through from the NiNTA column was concentrated in a centrifugal concentrator to $1 \mathrm{ml}$ and loaded onto a Superdex75 XK16/60 column (GE Healthcare) equilibrated in a buffer of $10 \mathrm{mM}$ Tris- $\mathrm{HCl} \mathrm{pH} \mathrm{8.0,}$ $250 \mathrm{mM} \mathrm{NaCl}$. Elution fractions containing C-LmGpsB were pooled, concentrated to $c .5 \mathrm{mg} / \mathrm{ml}$ in a centrifugal concentrator, and then dialyzed further into $20 \mathrm{mM}$ sodium phosphate $\mathrm{pH}$
$7.8,250 \mathrm{mM} \mathrm{NaCl}$ before finally flash freezing the protein in liquid nitrogen and storing at $-80^{\circ} \mathrm{C}$.

\section{Size exclusion chromatography}

The full-length wild-type $L m \mathrm{GpsB}$ and $L m \mathrm{GpsB}_{\mathrm{F} 91 \mathrm{~A}}$, $L m \mathrm{GpsB}_{\mathrm{F} 105 \mathrm{~A}}$ and $L m \mathrm{GpsB}_{\mathrm{F} 91 \mathrm{AF} 105 \mathrm{~A}}$ proteins were analyzed on a Superdex200 Increase 10/300 GL column (GE Healthcare) equilibrated in $10 \mathrm{mM}$ Tris- $\mathrm{HCl} \mathrm{pH} 8.0,250 \mathrm{mM} \mathrm{NaCl}$, at a flow rate of $0.5 \mathrm{ml} / \mathrm{min}$. Protein samples at $3 \mathrm{mg} / \mathrm{ml}$ concentration were injected onto the column through a $100 \mu \mathrm{l}$ sample loop. Wild-type $B s \mathrm{GpsB}$ and the $B s \mathrm{GpsB}_{\mathrm{T} 75 \mathrm{D}}$ and $B s \mathrm{GpsB}_{\mathrm{T} 75 \mathrm{E}}$ mutants were analyzed under the same conditions, except the protein concentration was $1 \mathrm{mg} / \mathrm{ml}$.

\section{Size exclusion chromatography-MALS}

GpsB samples $(500 \mu \mathrm{l})$ at concentrations of $8 \mathrm{mg} / \mathrm{ml}$ or $0.5 \mathrm{mg} / \mathrm{ml}$ were loaded onto a Superdex200 Increase 10/ 300 GL column (GE Healthcare) equipped with a Jasco UV2077 detector, Wyatt DAWN Heleos II EOS 18-angle laser photometer (with the 13th detector replaced with the QELS in-line dynamic light scattering detector) coupled to a Wyatt Optilab rEX refractive index detector. The flow rate was $0.75 \mathrm{ml} / \mathrm{min}$. Molecular mass and concentrations of the peaks eluting from the column in a running buffer of $10 \mathrm{mM}$ Tris$\mathrm{HCl} \mathrm{pH} 8.0,250 \mathrm{mM} \mathrm{NaCl}$ were analyzed using Astra 6.2 (www.wyatt.com/products/software/astra.html).

\section{Circular dichroism}

CD thermal melts were measured in a 1-mm path length quartz cuvette in a $20 \mathrm{mM}$ sodium phosphate $\mathrm{pH} 7.8,200 \mathrm{mM}$ $\mathrm{NaCl}$ buffer for wild-type $L m \mathrm{GpsB}, \mathrm{N}-L m \mathrm{GpsB}$, and C- LmGpsB and in $20 \mathrm{mM}$ sodium phosphate $\mathrm{pH} 7.8,250 \mathrm{mM}$ $\mathrm{NaCl}$ for wild-type $B s \mathrm{GpsB}, B s \mathrm{GpsB}_{\mathrm{T} 75 \mathrm{D}}$, and $B s \mathrm{GpsB}_{\mathrm{T} 75 \mathrm{E}}$. The temperature was increased at a rate of $1{ }^{\circ} \mathrm{C} / \mathrm{min}$, and ellipticity was monitored at a wavelength of $222 \mathrm{~nm}$ with a response time of 8 seconds and bandwidth of $2 \mathrm{~nm}$. The 
reversibility of the melts was verified by recording spectra in the wavelength range $200-240 \mathrm{~nm}$ (scan speed $20 \mathrm{~nm} / \mathrm{min}$, response 2 seconds) before and after the melt, to check that the spectra were superimposable. Protein concentrations were $23 \mu \mathrm{M}$ for wild-type $L m \mathrm{GpsB}, \mathrm{N}-L m \mathrm{GpsB}$, and C-LmGpsB, $29 \mu \mathrm{M}$ for $L m \mathrm{GpsB}_{\mathrm{F} 91 \mathrm{AF} 105}$, and $5 \mu \mathrm{M}$ for wild-type $B s \mathrm{GpsB}$, $B s \mathrm{GpsB}_{\mathrm{T} 75 \mathrm{D}}$, and $B s \mathrm{GpsB}_{\mathrm{T} 75 \mathrm{E}}$.

The $\mathrm{CD}$ spectra of wild-type and $\mathrm{C}-L m \mathrm{GpsB}_{\mathrm{F} 105 \mathrm{~A}}$ proteins were recorded at protein concentrations of 23 and $33 \mu \mathrm{M}$, respectively, in a buffer of $20 \mathrm{mM}$ sodium phosphate $\mathrm{pH} 7.8$ at $20^{\circ} \mathrm{C}$. The scan speed was $10 \mathrm{~nm} / \mathrm{min}$, and the response time was 4 seconds. Protein concentrations were determined based on calculated extinction coefficients at $280 \mathrm{~nm}^{29}$ for $L m \mathrm{GpsB}, \mathrm{N}-L m \mathrm{GpsB}$, and $B s \mathrm{GpsB}$ proteins; for the C-LmGpsB proteins, which lack tryptophan and tyrosine residues, amino acid analysis was used instead to quantify concentration. Secondary structure composition was evaluated from the spectra using the program $\operatorname{CDSSTR}^{30}$ within the DICHROWEB ${ }^{31}$ server.

\section{SAXS data collection and processing}

The $L m \mathrm{GpsB}$ and $\mathrm{N}-L m \mathrm{GpsB}$ proteins were analyzed in a buffer of $10 \mathrm{mM}$ Tris- $\mathrm{HCl} \mathrm{pH} 8.0,150 \mathrm{mM} \mathrm{NaCl}$ at a protein concentration of $40 \mathrm{mg} / \mathrm{ml}$. SAXS intensity data, $I(q)$ versus $q,(q=4 \pi \sin 2 \theta / \lambda$, where $2 \theta$ is the scattering angle $)$ were collected using batch-mode SAXS on beamline P12 at PETRAIII (DESY; Hamburg), or batch mode and inline size exclusion chromatography (SEC)-SAXS on beamline B21, Diamond Light Source. Batch-mode SAXS was completed using $30 \mu \mathrm{l}$ of $L m \mathrm{GpsB}$ or $\mathrm{N}-L m \mathrm{GpsB}$ in a dilution series, which was loaded onto the beamline using the EMBL automated sample changer. ${ }^{32}$ SAXS data were collected at PETRAIII with 0.5 second exposures onto a $2 \mathrm{M}$ Pilatus detector (Dectris) at a distance of $3.0 \mathrm{~m}$ and an X-ray wavelength of $1.24 \AA$; these data were reduced and subtracted using in-house software. $^{33}$

For SEC-SAXS data collection at Diamond, $50 \mu \mathrm{l}$ of $L m G$ psB was loaded onto a Superdex 200 Increase 3.2/300 column and the eluent flowed through the SAXS beam at a flow rate of $0.1 \mathrm{ml} / \mathrm{min}$; the buffer used as the blank in these measurements was the eluent after one SEC column volume. SAXS data were constantly collected at 1 second intervals using a $2 \mathrm{M}$ Pilatus detector (Dectris) at a distance of $3.9 \mathrm{~m}$ and an X-ray wavelength of $1 \AA$. Subtraction of the SECSAXS data was completed for each frame across the elution peak, and the radius of gyration $\left(\mathrm{R}_{\mathrm{g}}\right)$ and the integral of ratio to background were plotted. The data were scaled, merged, and averaged for each frame with a consistently similar $\mathrm{R}_{\mathrm{g}}$. All further processing and analysis of data were carried out using ScÅtter (www.bioisis.net/scatter).

Pair distance distribution functions were calculated with GNOM ${ }^{34}$ with $\mathrm{D}_{\max }$ values for $L m \mathrm{GpsB}$ and $\mathrm{N}-L m \mathrm{GpsB}$ of 185 and $76 \AA$; the $D_{\text {max }}$ values were estimated initially using DATGNOM and the atomic coordinates of $\mathrm{N}-L m \mathrm{GpsB},{ }^{11}$ from which the pair distance distribution function was calculated with ScÅtter; all waters and heteroatoms were removed before the calculation.

\section{SAXS model generation}

Dummy atom models were constructed in DAMMIN in slow mode using scattering data up to a maximum $q$ value of
$8 / \mathrm{R}_{\mathrm{g}}\left(0.15 \AA^{-1}\right.$ for $L m \mathrm{GpsB}, 0.36 \AA^{-1}$ for $N$-LmGpsB). For $\mathrm{N}-L m \mathrm{GpsB}$, the chi-squared values calculated by DAMMIN, corresponding to the agreement between experimental scattering curves and scattering curves calculated from the dummy atom models, ranged between 1.60 and 1.64. For $L m \mathrm{GpsB}$, the chi-squared values from individual DAMMIN run were in the range 1.11-1.14. For $\mathrm{N}-L m \mathrm{GpsB}$, the average normalized structural discrepancy (NSD) between models from 10 independent DAMMIN runs, after averaging them together in the DAMAVER suite, ${ }^{35}$ was $0.539 \pm 0.09$. For $L m \mathrm{GpsB}$, the models from 15 DAMMIN runs were superimposed and averaged in the DAMAVER suite and the averaged model was then input into DAMSTART to generate a starting model for a further 15 DAMMIN runs. The final models were then again averaged together using the DAMAVER suite; the NSD between models was $0.552 \pm 0.09$.

Dummy atom models were visualized in CHIMERA ${ }^{36}$ by representing the atoms as beads, with the bead scale adjusted to a value equivalent to the dummy atom radius divided by 0.7. The surface mesh representation of dummy atom models was generated by using the CHIMERA "molmap" command to convert the model to the equivalent electron density map at $25 \AA$ resolution - the contouring of this map was then adjusted to enclose the surface of the dummy atoms. The crystal structures of the $\mathrm{N}$ - and C-terminal domains of $\mathrm{GpsB}^{11}$ PDBids 4ug1 and 5an5, respectively, were also represented as $25 \AA$ resolution electron density maps using the "molmap" command in CHIMERA. For the LmGpsB sample, the molecular weight of the scattering particles was calculated from the volume of correlation ${ }^{37}$ using ScAttter.

\section{Production of lipid II-meso-diaminopimelic acid}

Lipid II-meso-diaminopimelic acid (Lipid II- $m$-DAP) was synthesized using UDP-MurNAc-pentapeptide isolated from Bacillus cereus, essentially as described previously ${ }^{38,39}$ with the following modifications. Purification was performed over a DEAE-cellulose column using a linear gradient of chloroform/methanol/water $(2: 3: 1 \mathrm{v} / \mathrm{v} / \mathrm{v})$ to chloroform/methanol/ $1 \mathrm{M}$ ammonium bicarbonate $(2: 3: 1 \mathrm{v} / \mathrm{v} / \mathrm{v})$. The fractions containing Lipid II- $m$-DAP were collected and dried under vacuum. The resulting lipid II- $m$-DAP was then dissolved in 1:1 chloroform:methanol and stored at $-20^{\circ} \mathrm{C}$ until use.

\section{Production of $\left[{ }^{14} \mathrm{C}\right]$-amidated Lipid II-m-DAP}

The ability of MurG to exchange the GlcNAc group between UDP-GlcNAc and Lipid II was used to radioactively label Lipid II. Since the E. coli MurG used here displayed much lower affinity for amidated Lipid II- $m$-DAP than the nonamidated form, we first synthesized $\left[{ }^{14} \mathrm{C}\right]$-Lipid II- $m$-DAP and then amidated this using AsnB from B. subtilis. First, $1.22 \mu \mathrm{mol}$ of purified lipid II- $m$-DAP was incubated with $12.5 \mu \mathrm{Ci}$ of UDP- $N$-acetyl-D-[1- $\left.{ }^{14} \mathrm{C}\right]$ glucosamine (specific activity $55 \mathrm{mCi} / \mathrm{mmol}$ ) (Hartmann Analytic $\mathrm{GmbH}$ ). The labeling reaction was performed in $1 \mathrm{ml}$ of $100 \mathrm{mM}$ Tris- $\mathrm{HCl}, \mathrm{pH}$ 8.0, $1 \mathrm{mM} \mathrm{MgCl}_{2}$, and $2 \%(\mathrm{w} / \mathrm{v})$ Triton $\mathrm{X}-100$. The reaction was started by the addition of $1 \mu \mathrm{L}$ purified recombinant $E$. coli MurG, which is able to exchange the $N$-acetyl-D-glucosamine of lipid II with that of UDP- $N$-acetyl-D- $\left[1-{ }^{14} \mathrm{C}\right]$ glucosamine. After incubation at room temperature for 2.5 hours, the reaction was complete as determined by liquid scintillation counting. 
To amidate the carboxylic acid group of the $m$-DAP, lipid II-DAP was incubated with B. subtilis AsnB in the presence of ATP and glutamine (to be published elsewhere), followed by extraction using butanol/pyridine acetate, $\mathrm{pH} 4.2$, and another purification step over a DEAE cellulose column using a gradient of chloroform/methanol/water $(2: 3: 1 \mathrm{v} / \mathrm{v} / \mathrm{v})$ to chloroform/methanol/ $0.5 \mathrm{M}$ ammonium bicarbonate $(2: 3: 1 \mathrm{v} / \mathrm{v} / \mathrm{v})$.

\section{In vitro peptidoglycan synthesis assays}

The continuous fluorescence glycosyltransferase (GTase) assay using dansyl-labeled lipid II as the substrate was performed essentially as described previously, ${ }^{40}$ with only minor modifications to buffer conditions and temperature. We also used an endpoint assay to measure the GTase and transpeptidase (TPase) activity under the same experimental conditions. The activity of $B s \mathrm{PBP} 1(0.4 \mu \mathrm{M})$ was measured at $37^{\circ} \mathrm{C}$ in the absence and presence of $10 \mu \mathrm{M} B s \mathrm{GpsB}$ proteins in $50 \mathrm{mM}$ HEPES.NaOH pH 7.5, $20 \mathrm{mM} \mathrm{NaCl}$, $10 \mathrm{mM} \mathrm{CaCl} 2$, and $5 \%(\mathrm{v} / \mathrm{v})$ glycerol. The endpoint assay used $\left[{ }^{14} \mathrm{C}\right]$-labeled native amidated lipid II- $m$-DAP substrate followed by the quantification of both GTase and TPase products by high-pressure liquid chromatography (HPLC) as described previously. ${ }^{41}$

\section{Results}

\section{Low resolution model of subunit arrangement} in solution by SAXS

In the absence of diffracting crystals of full-length $L m G p s B$, SAXS was used to determine its low resolution structure since the correct assembly of subunits in $L m G \mathrm{GsB}$ is highly pertinent to the protein's function. To validate this approach, we first analyzed N-LmGpsB for which the crystal structure has already been solved. ${ }^{11}$ The measured scattering

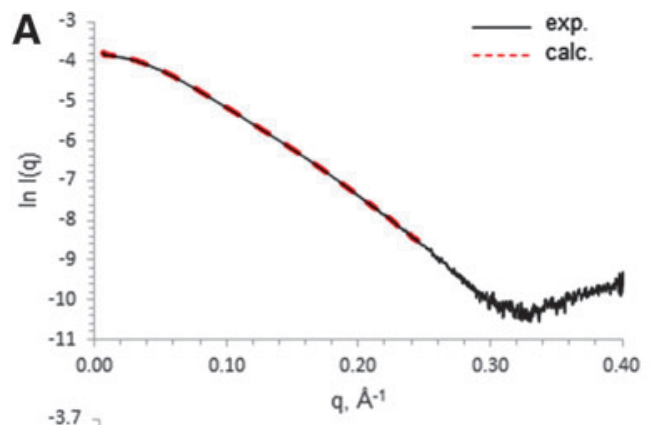

B
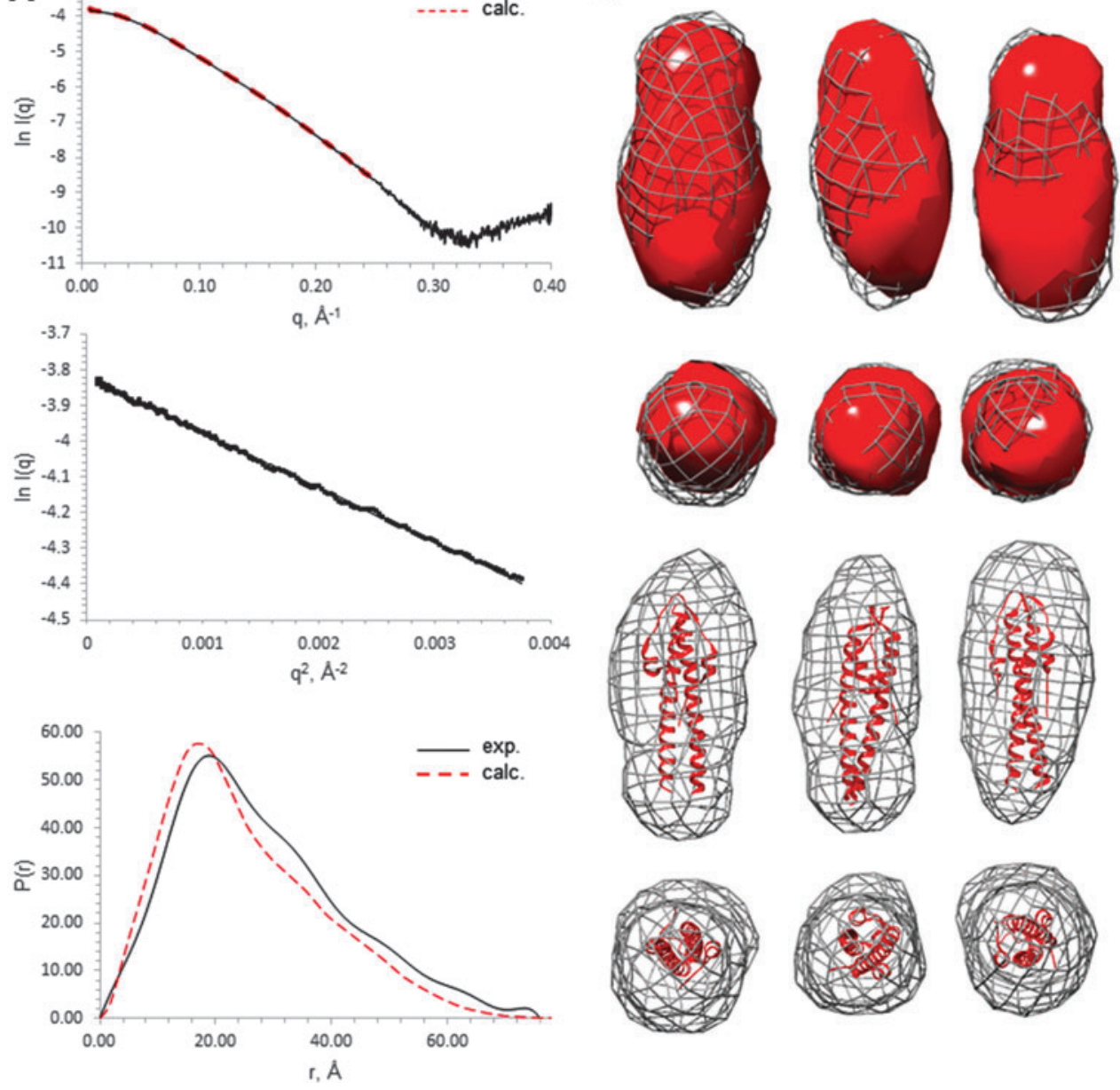

FIG. 1. SAXS analysis of N-LmGpsB. (A) SAXS scattering curves (top), Guinier plots (middle), and pair distribution functions (bottom) for $\mathrm{N}-L m \mathrm{GpsB}$. The experimentally observed scattering curve is shown as a black solid line and the scattering curve, calculated from the coordinates with CRYSOL (42), as a red dashed line. The chi-squared value for the agreement between the two curves in the $q$ range $0-0.25 \AA^{-1}$ is 1.8 . For the pair distribution function of the $\mathrm{N}-L m \mathrm{GpsB}$, the red dashed plot represents the profile calculated from the coordinates with the ScAtter software. (B) SAXS-derived ab-initio dummy atom models of N-LmGpsB calculated with DAMMIN from small-angle X-ray scattering profiles. Representative models are shown from three independent DAMMIN calculations. The dummy atom model is shown in surface representation rendered in mesh. The coordinates of the $\mathrm{N}-L m \mathrm{GpsB}$ dimer (red) have been manually docked inside the mesh, represented either in ribbon form or as the equivalent electron density maps would appear at $25 \AA$. SAXS, small-angle X-ray scattering. 
profile for $\mathrm{N}-L m \mathrm{GpsB}$ matched favorably with the theoretical profile calculated from the corresponding atomic coordinates (Fig. 1A). From a Guinier analysis of the scattering profile, an $R_{g}$ of $21.4 \AA$ was obtained, while the pair distribution function calculated by inverse Fourier transformation with $\mathrm{GNOM}^{34}$ gave an $\mathrm{R}_{\mathrm{g}}$ of $22.2 \AA$. These values compare extremely favorably with an $R_{g}$ value of $21.4 \AA$ that was calculated from the atomic coordinates with CRYSOL. ${ }^{42}$ Finally, $a b$ initio dummy atom molecular models built from the scattering data with DAMMIN ${ }^{43}$ reproduced well the shape and dimensions of the dimeric $\mathrm{N}$ -LmGpsB (Fig. 1B).

Analysis of $L m G$ psB yielded the best quality data on SAXS beamlines with an in-line SEC facility. The monodispersity of $L m G$ psB samples after in-line SEC was indicated by the linearity of Guinier plots at $q$ values less than $1.3 / \mathrm{R}_{\mathrm{g}}$ (Fig. 2A). The molecular mass of the scattering particles after in-line SEC, calculated from the volume of correlation, ${ }^{37}$ was $75,900 \mathrm{Da}$, which is within $5 \%$ of the actual mass of the expressed $L m \mathrm{GpsB}$ protein when assembled as a hexamer.

A Porod-Debye analysis of the comparative flexibility of LmGpsB and $\mathrm{N}-L m \mathrm{GpsB}$ suggested that the full-length protein is more flexible than the isolated N-terminal domain. The Porod-Debye plot for $\mathrm{N}-L m \mathrm{GpsB}$ rose to a plateau (Fig. 2B), which is characteristic of a folded compact pro- tein. ${ }^{44}$ By contrast, the Porod-Debye plot for $L m G$ psB had a less pronounced plateau and instead conformed to a hyperbole. The relatively shallow gradient of the asymptote, however, indicated that $L m \mathrm{GpsB}$ is markedly less flexible than a completely unfolded protein. Given the successful crystal structure determinations of both $\mathrm{N}$ - and C-terminal domains of $\mathrm{GpsB}$, the flexibility within $L m \mathrm{GpsB}$ is most likely attributable to the linker region between the domains.

The pair distribution function of $L m \mathrm{GpsB}$ had, like $\mathrm{N}$ $-L m \mathrm{GpsB}$, the characteristics of an elongated molecule, ${ }^{45}$ with a steep initial increase in $\mathrm{P}(\mathrm{r})$ to a maxima followed by a more gradual decrease to zero at $\mathrm{D}_{\max }$. From the Guinier plot and pair distribution functions, $\mathrm{R}_{\mathrm{g}}$ values of 51.2 and $53.1 \AA$ were obtained for $L m \mathrm{GpsB}$. Ab initio dummy atom molecular models were calculated in DAMMIN without symmetry constraints, however, no obvious symmetric relationships were apparent from the resultant models. A notable feature of the models is two distinct lobes of different sizes connected by a narrower central region (Fig. 3).

The most logical arrangement of the individual domains in the GpsB hexamer resembles a tripod with the three dimeric N-GpsB domains aligned as in the legs in a tripod with the two C-GpsB trimeric domains encompassing its base (Fig. 4A). Such an arrangement is logical on the basis that it presents a relatively straight path and near equivalent distance between connected $\mathrm{C}$ - and $\mathrm{N}$-terminal domains of
A
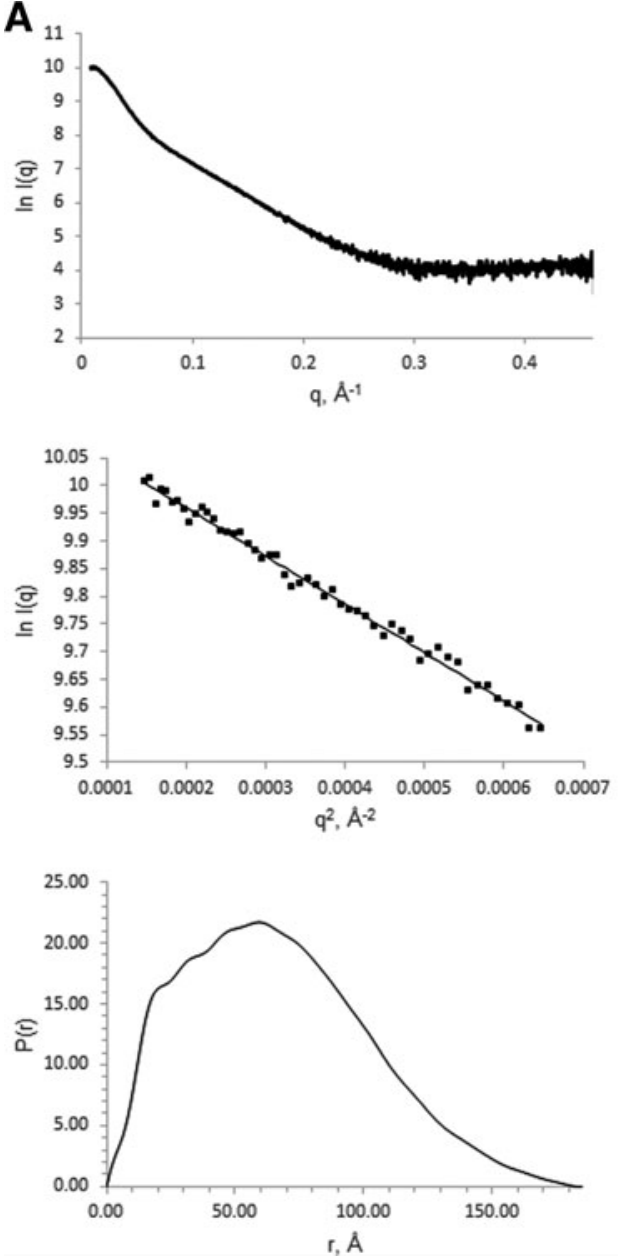
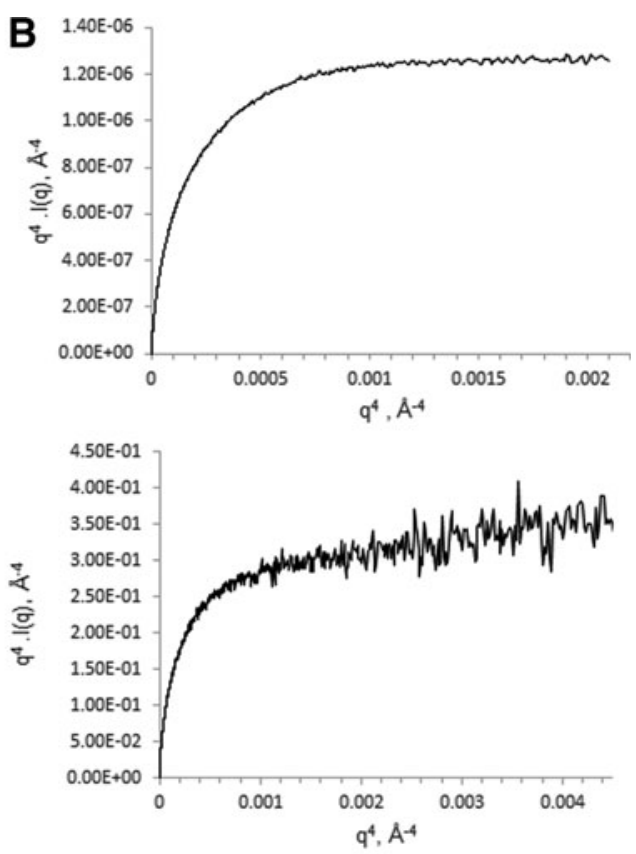

FIG. 2. SAXS analysis of LmGpsB. (A) SAXS scattering curves (top), Guinier plots (middle), and pair distribution functions (bottom) for $L m \mathrm{GpsB}$. (B) Analysis of the flexibility of the N- LmGpsB (top) and the LmGpsB protein (bottom) by Porod-Debye plots. The plateau in the plot for $\mathrm{N}$ -

$-L m \mathrm{GpsB}$ is consistent with a compact folded protein. 
FIG. 3. SAXS molecular envelopes for $L m \mathrm{GpsB}$. (A) The average surface of 15 independently generated $a b$ initio LmGpsB dummy atom models is represented as a mesh. Three of these models are represented in (B) to illustrate the level of variation. The coordinates of N-LmGpsB dimers (red and cyan) and the C-LmGpsB trimers (blue) were docked manually and are shown in ribbon form (right column) or as equivalent electron density maps would appear at $25 \mathrm{~A}$ resolution (left, middle columns). The coordinates shown correspond to residues 5-67 (N-terminal domain) and 89-106 (Cterminal domain) of $\mathrm{Lm} \mathrm{GpsB}$; LmGpsB has a total of 113 residues. The models do not include the linker between domains. In the arrangements shown in (B), with the simplest of the possible connectivities between domains, the chain termini are separated by distances of up to $55 \AA$. By comparison, a fully extended 21 polypeptide residue chain would be $\sim 80 \mathrm{~A}$ in length, and therefore, the models are compatible with the domains being connected by an appropriate length linker in a semicompact conformation.
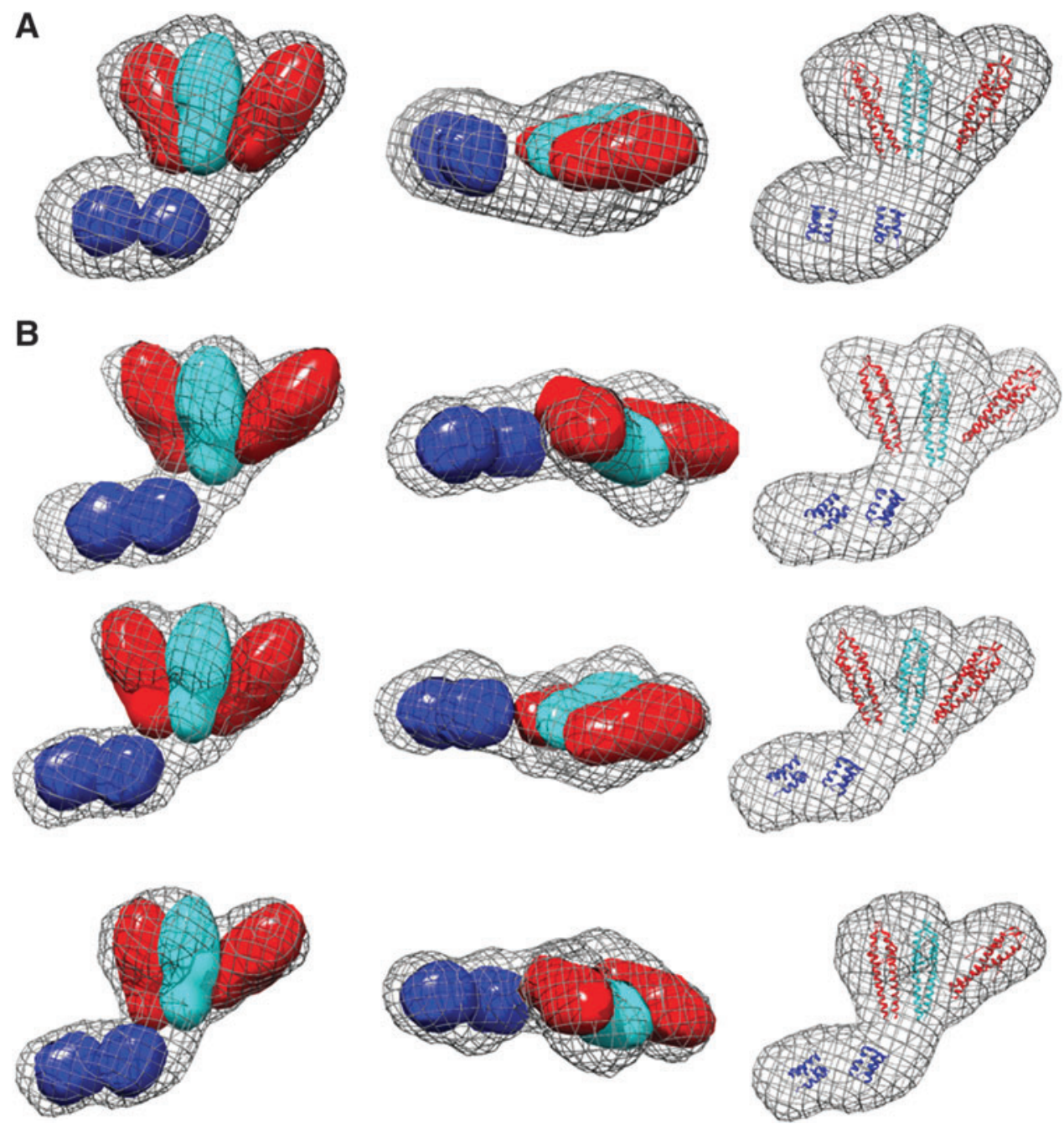

the F91A mutation substantially increased the retention volume of $L m \mathrm{GpsB}$ mutants on SEC analysis relative to the wild-type $L m G$ GsB (Fig. 5A). Subsequent SEC-MALS analysis of the $L m \mathrm{GpsB}_{\mathrm{F} 91 \mathrm{AF} 105 \mathrm{~A}}$ double mutant confirmed this is due to a change in the oligomeric state; the double mutant formed a trimer at high protein concentrations and a dimer at lower concentrations (Fig. 5B). Mutation of F91A alone had an intermediate effect on assembly, with SEC analysis revealing two species; the predominant peak has a similar retention volume as the hexameric wild-type protein, while the other peak has a retention volume more similar to the F91AF105A double mutant (Fig. 5B).

The structural importance of F91 and F105 is further supported by thermal stability analysis using circular dichroism spectroscopy. Wild-type $L m \mathrm{GpsB}$ has a $\mathrm{T}_{\mathrm{m}}$ (the temperature of the midpoint of thermal unfolding) of $50^{\circ} \mathrm{C}$, whereas the $L m \mathrm{GpsB}_{\mathrm{F} 91 \mathrm{AF} 105 \mathrm{~A}}$ double mutant has a $\mathrm{T}_{\mathrm{m}}$ of $45^{\circ} \mathrm{C}$ (Fig. $6 \mathrm{~A}$ ). At the protein concentrations used for the $\mathrm{CD}$ analysis, the $L m \mathrm{GpsB}_{\mathrm{F} 91 \mathrm{AF} 105 \mathrm{~A}}$ double mutant was observed to be a dimer on SEC-MALS analysis (Fig. 6B), which may explain why $L m \mathrm{GpsB}_{\mathrm{F} 91 \mathrm{AF} 105 \mathrm{~A}}$ has a similar $\mathrm{T}_{\mathrm{m}}$ as the dimeric, isolated $\mathrm{N}-L m \mathrm{GpsB}$ domain (Fig. 6A).

To further investigate the structural role of F105, the alanine substitution was made within the context of the 

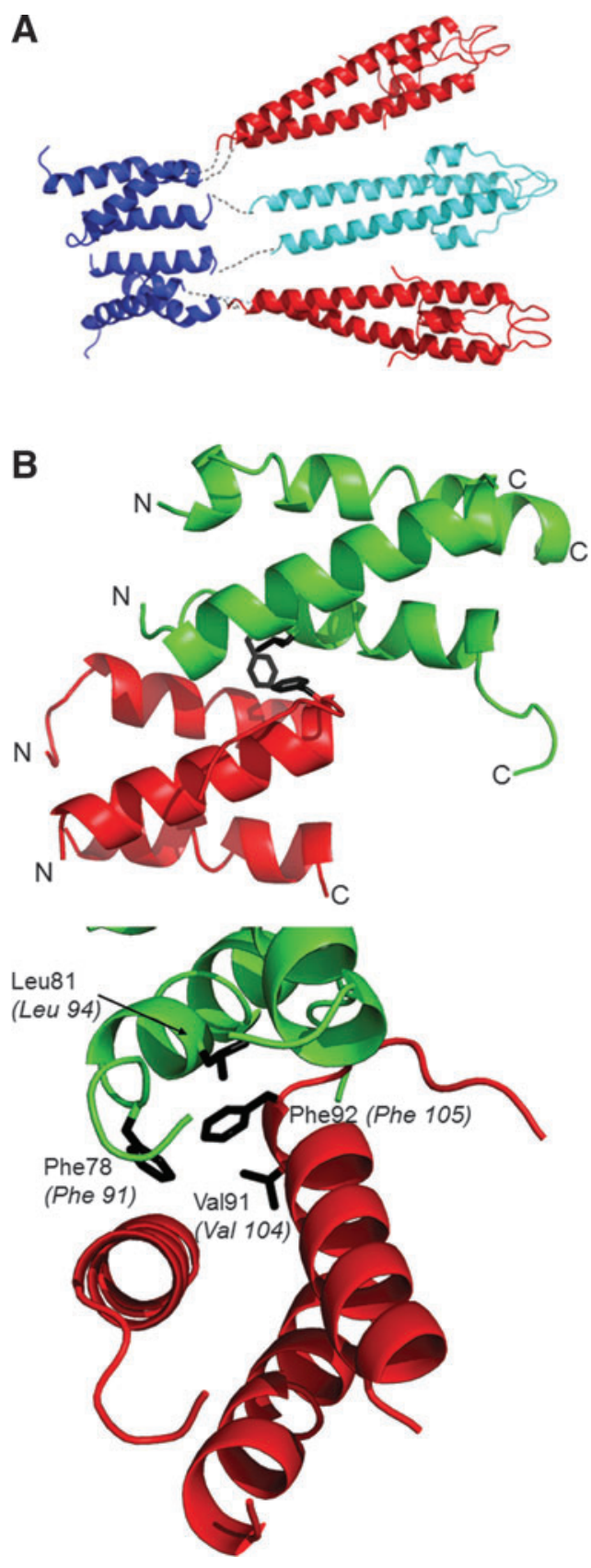

FIG. 4. Interaction between GpsB domains. (A) A priori hypothetical arrangement of the $\mathrm{N}$ - and $\mathrm{C}$-terminal domains of $\mathrm{GpsB}$, as described in the text. N-LmGpsB dimers are colored cyan and red; $\mathrm{C}-L m \mathrm{GpsB}$ trimers blue. The putative path taken by interdomain linkers is represented as a black dotted line. Note the N-LmGpsB dimer colored cyan is covalently linked to two separate $\mathrm{C}-L m \mathrm{GpsB}$ trimers and thus forms a bridge between two trimers that would stabilize association into a hexamer. (B) The interface between adjacent (red and green) C-BsGpsB molecules as observed in its crystal lattice, with the key hydrophobic interfacial residues F78, L81, and F92 drawn as sticks and colored black. The lower panel also shows V91, a residue in the hydrophobic core of the $\mathrm{C}-B s \mathrm{GpsB}$ trimer, which packs against the interfacial residue F92. In the lower panel, the numbering of the Listeria monocytogenes GpsB equivalents of BsGpsB F78, L81, V91, and F92 is shown in italics in parentheses. isolated C-terminal domain. The isolated C-terminal domain forms trimers, rather than hexamers, in solution, ${ }^{11}$ and F105 is exposed on the surface of this trimer, rather than in the hydrophobic core. F105 is unlikely to have an important structural role within the isolated C-terminal domain, but will stabilize the hexameric full-length protein. However, the $\mathrm{C}-L m \mathrm{GpsB}_{\mathrm{F} 105 \mathrm{~A}}$ fold was markedly destabilized as the alpha helical content was reduced from $70 \%$ in the wild-type $\mathrm{C}-L m \mathrm{GpsB}$ protein to $10 \%$ in the F105A mutant. This effect can perhaps be reconciled on closer analysis of the structure of $\mathrm{C}-\mathrm{Bs} \mathrm{GpsB}$; F92 (equivalent to F105 in L. monocytogenes $\mathrm{GpsB}$ ) is in close proximity to the hydrophobic core residue V91, and while one face of the F92 aromatic ring is surface exposed, the other face packs against V91 (Fig. 4B). The structural importance of F105 may therefore have two components; first, F105 stabilizes indirectly the folding of the isolated $\mathrm{C}$-terminal domain because of its interaction with Val104, and second, F105 is likely to stabilize further interactions between C-GpsB trimers within the GpsB hexamer, by packing against Phe91 and Leu94 in another protomer in the hexamer (Fig. 4B). The dimers and trimers observed with the $L m \mathrm{GpsB}_{\mathrm{F} 91 \mathrm{AF} 105 \mathrm{~A}}$ double mutant likely arose from misfolding of at least the C-terminal domain, given the loss of secondary structure associated with the F105A mutation (Fig. 6A).

To validate the effect of mutations in the interface between C-GpsB trimers, we used a complementation assay to measure the effect of gps $B$ mutations on GpsB activity in L. monocytogenes. Briefly, the L. monocytogenes $\Delta$ gpsB mutant grew equally well as the wild-type strain at $30^{\circ} \mathrm{C}$ and was still viable at $37^{\circ} \mathrm{C}$; however, the L. monocytogenes $\triangle$ gps $B$ mutant was not viable at $42^{\circ} \mathrm{C}$, neither were $g p s B$ mutants affected in self-interactions or interactions with the L. monocytogenes orthologue of B. subtilis PBP1, PBP A1 (for simplicity referred to herein as PBP1). ${ }^{11}$ Mutations that individually exchanged the pair of phenylalanines (F91, F105, the equivalent B. subtilis residues are highlighted on the structure in Figure 4) and the adjacent L94 into alanines were introduced to L. monocytogenes gpsB, and the resulting alleles were tested in the complementation assay. As shown in Fig. 7A, the wild-type L. monocytogenes strain EGD-e proliferated readily at $42^{\circ} \mathrm{C}$, whereas the $\Delta g p s B$ mutant (strain LMJR19) was unable to grow at all at this temperature. Reintroduction of wild-type gps $B$ into the $\Delta g p s B$ mutant (strain LMS56) repaired this defect, demonstrating successful complementation. The point mutations introduced fell into two classes: strain LMS185, expressing $g p s B_{F 91 A}$ was able to grow at $42^{\circ} \mathrm{C}$, although with increased autolysis in the stationary phase as observed by phase contrast microscopy (not shown) and by growth curve analysis (Fig. 7A), suggesting that the in vivo activity of $L m \mathrm{GpsB}_{\mathrm{F} 91 \mathrm{~A}}$ was partially impaired. By contrast, mutations L94A and F105A completely prevented growth of strains LMS186 and LMS187, respectively (Fig. 7A), indicating that these amino acid exchanges generated biologically inactive GpsB proteins. Western blotting showed that all the GpsB mutant proteins were expressed both during growth at $37^{\circ} \mathrm{C}$, where all strains are viable (Fig. 7C), and also 2 hours after a temperature shift to $42^{\circ} \mathrm{C}$ (Fig. 7D). The loss of growth at $42^{\circ} \mathrm{C}$ is therefore more likely to result from a loss of a functional property of GpsB rather than a loss of protein production or its degradation. 


\section{Role of the phosphorylation of GpsB}

It has been reported recently that GpsB was phosphorylated in B. subtilis cells at T75 (T88 in LmGpsB) by the kinase PrkC. ${ }^{19}$ The phosphomimetic mutations T75D and $\mathrm{T} 75 \mathrm{E}$ appeared to have the same salt-sensitive phenotype as
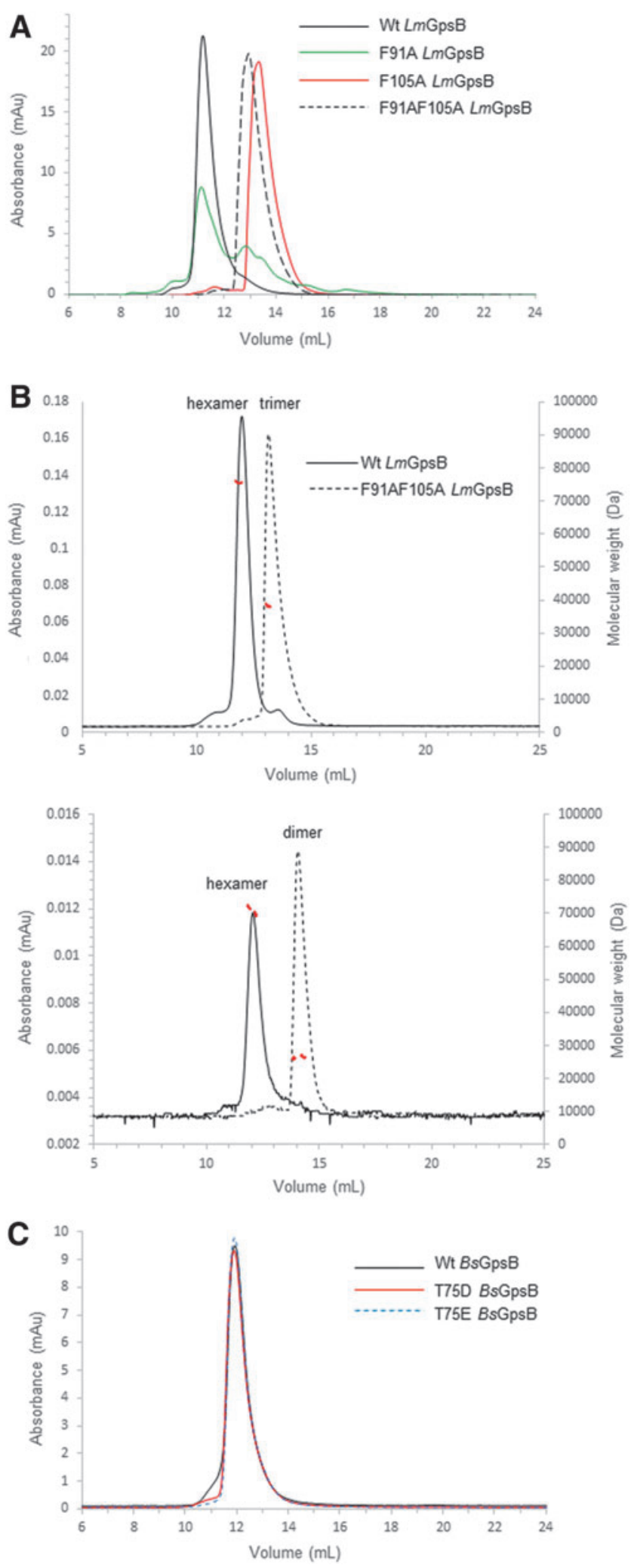

a $g p s B$ deletion. ${ }^{19}$ Likewise, we found that the introduction of the analogous T88D exchange into $L m \mathrm{GpsB}$ almost completely inactivated the protein. However, the phosphoablative T88A mutation was without effect on complementation activity of $L m G p s B$ (Fig. 7B, D). T75 in BsGpsB and T88 in $L m G$ psB are located in the linker between the two domains. To investigate whether the T75E and T75D mutations had any impact on the hexamerization of $B s \mathrm{GpsB}$, fulllength, wild-type, T75E and T75D mutant $B s \mathrm{GpsB}$ proteins $\left(B s \mathrm{GpsB}_{\mathrm{T} 75 \mathrm{E}}\right.$ and $\left.B s \mathrm{GpsB}_{\mathrm{T} 75 \mathrm{D}}\right)$ were analyzed by $\mathrm{SEC}$ in conditions under which wild-type $B s \mathrm{GspB}$ was shown by SEC-MALS to form a stable hexamer. ${ }^{11}$ The T75E and the T75D mutations did not have a major effect on the size exclusion chromatograms of $B s \mathrm{GpsB}$; the major species in wild-type and both mutant proteins had an identical retention volume (Fig. 5C). Similarly, thermal denaturation analysis by circular dichroism did not reveal any marked difference in the structural stability of wild-type $B s \mathrm{GpsB}$ and the T75D and T75E mutants (Fig. 6C).

\section{Effect of BsGpsB on the glycosyltransferase and transpeptidase activity of BsPBP1 in vitro}

To explore the functional role of GpsB and the relationship to its structure, the effect of $B s \mathrm{GpsB}$ on the GTase and TPase activities of $B s$ PBP1 was investigated. BsPBP1 was used as both the TGase and TPase activities of this enzyme have successfully been recapitulated in vitro, ${ }^{46}$ which is not yet the case for the listeria PBPs. Both wild-type and phosphomimetic T75D/T75E mutants of $B s \mathrm{GpsB}$ were used in these experiments in case any modulation of PBP1 activity by $\mathrm{GpsB}$ requires prior phosphorylation of $\mathrm{GpsB}$. The GTase activity of BsPBP1 was monitored using a fluorescence assay, in which the polymerization of fluorescently labeled lipid II followed by digestion of the resulting glycan chains by a muramidase results in a reduction of fluorescence intensity with time, correlated with the rate of the reaction. The addition of a twenty five-fold excess of either wild-type or the phosphomimetic T75D/T75E mutants of

FIG. 5. SEC and SEC-MALS analysis of GpsB proteins. (A) SEC analysis of wild-type LmGpsB (solid black line), Lm $\mathrm{GpsB}_{\mathrm{F91A}}$ (solid green line), Lm $\mathrm{GpsB}_{\mathrm{F} 105 \mathrm{~A}}$ (solid red line), and $L m \mathrm{GpsB}_{\mathrm{F} 91 \mathrm{AF} 105 \mathrm{~A}}$ (dashed black line) proteins at $3 \mathrm{mg} / \mathrm{ml}$ concentration. (B) SEC-MALS analysis of wildtype LmGpsB (solid black line) and $L m \mathrm{GpsB}_{\mathrm{F} 91 \mathrm{AF} 105 \mathrm{~A}}$ (dashed black line) proteins. The chromatograms represent analysis at two injected protein concentrations of $8 \mathrm{mg} / \mathrm{ml}$ (top) and $0.5 \mathrm{mg} / \mathrm{ml}$ (bottom). The deconvoluted molecular masses of the eluting species (red dashed lines) are plotted on the right hand axis. The average of $76 \mathrm{kDa}$ and $38.9 \mathrm{kDa}$ across the major peak for wild-type $L m \mathrm{GpsB}$ and $L m \mathrm{GpsB}_{\mathrm{F} 91 \mathrm{AF} 105 \mathrm{~A}}$ at $8 \mathrm{mg} / \mathrm{ml}$ is consistent with the theoretical mass of a hexamer $(79 \mathrm{kDa})$ and trimer $(38.6 \mathrm{kDa})$. At lower protein concentrations, the average mass of $L m \mathrm{GpsB}_{\mathrm{F} 91 \mathrm{AF} 105 \mathrm{~A}}$ is $26 \mathrm{kDa}$, consistent with the theoretical mass of a dimer $(25.8 \mathrm{kDa})$, whereas the wild-type $L m \mathrm{GpsB}$ remains hexameric. (C) SEC of wild-type $B s \mathrm{GpsB}$ (solid black line), BsGpsB $\mathrm{T}_{\mathrm{T} 75 \mathrm{E}}$ (dashed blue line), and $B s \mathrm{GpsB}_{\mathrm{T} 75 \mathrm{D}}$ (solid red line) mutants, all at $1 \mathrm{mg} / \mathrm{ml}$. These phosphomimetic mutations do not introduce any significant change to the oligomeric state of $B s \mathrm{GpsB}$. SEC, size exclusion chromatography. 

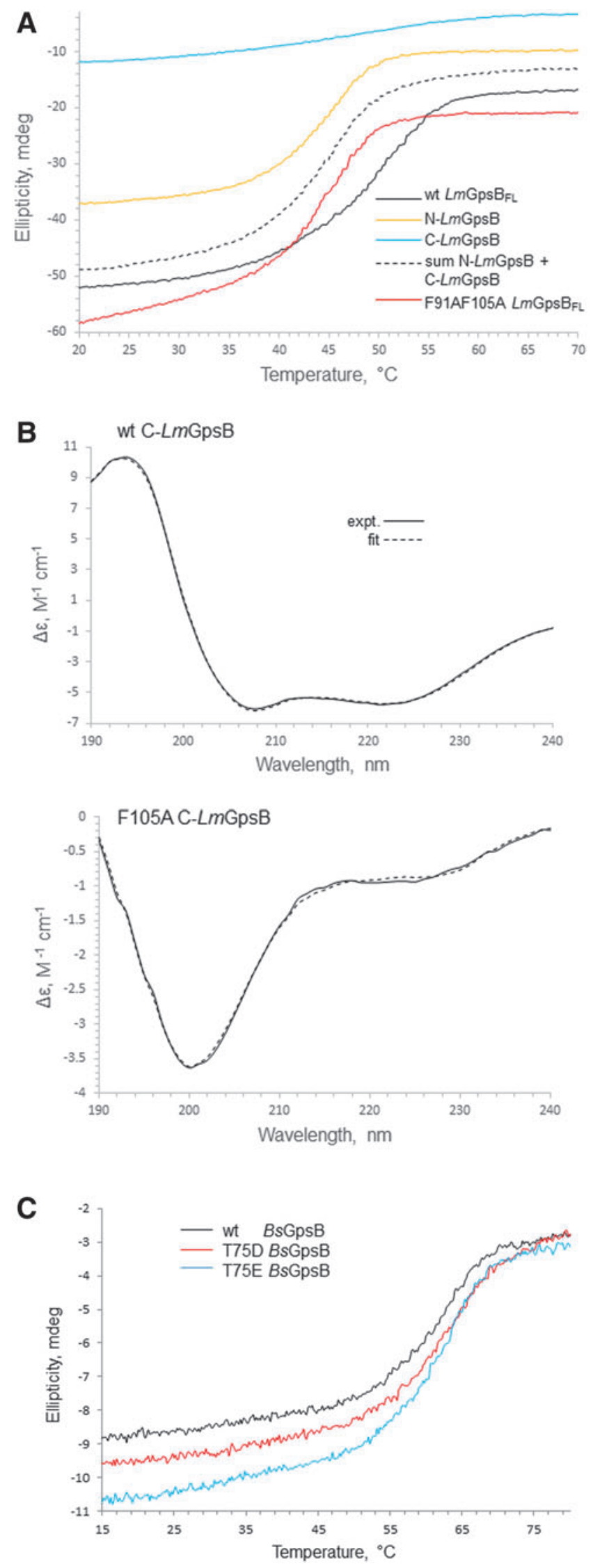

$B s G p s B$ had no apparent effect on the rate of the GTase reaction catalyzed by $B s \mathrm{PBP} 1$ (Fig. $8 \mathrm{~A}$ ).

The effect of $B s \mathrm{GpsB}$ on $B s \mathrm{PBP} 1$ was explored further using a HPLC-based in vitro PG synthesis assay ${ }^{41}$ to monitor the composition of peptidoglycan synthesized by $B s \mathrm{PBP} 1$ in the presence and absence of $B s \mathrm{GpsB}$. Consistent with others' previous observations, ${ }^{46}$ BsPBP1 was active as a TPase when assayed with a native lipid II substrate that had been amidated at the $\varepsilon$-carboxylate of meso-diaminopimelic acid (lipid II- $m$-DAP). In this endpoint assay, PBP1 produced peptidoglycan with approximately $30 \%$ of the peptides present in cross-links, irrespective of the absence or the presence of a twenty five-fold molar excess of either wildtype or the phosphomimetic T75D/T75E mutants of $B s \mathrm{GpsB}$ (Fig. 8B). As observed with other PBPs ${ }^{39}$ BsPBP1 also exhibited a weak DD-carboxypeptidase activity that was unaffected by the presence of any $B s G p s B$ protein tested. Since $B s \mathrm{GpsB}$ interacts with $B s \mathrm{PBP} 1$ with a $K_{\mathrm{d}}$ of $0.7 \mu \mathrm{M},{ }^{11}$ at the protein concentrations used in both assays BsPBP1 should be bound to $B s \mathrm{GpsB}$, suggesting that the interaction has no discernible effect on either the GTase or the TPase activities of BsPBP1 in vitro.

\section{Discussion}

The quaternary structure and the connectivity between domains in GpsB are an intriguing geometric puzzle; GpsB is a hexamer, while the isolated $\mathrm{N}$ - and $\mathrm{C}$-terminal domains are dimeric and trimeric, respectively. The arrangement of the domains from the SAXS analysis resembles a logical tripod arrangement, but with a more asymmetric shape than perhaps predicted a priori. The asymmetry may be driven, at least in part, by the interactions between C-GpsB trimers; the SAXS envelope suggests a "staggered" alignment of the two C-GpsB trimers, in which one of the trimers is closer to the center of mass of the GpsB hexamer than the other (Fig. 3). A similar staggered alignment is observed in the crystal packing of $\mathrm{C}-B s \mathrm{GpsB}$. In this case, each trimeric $\mathrm{C}-B s \mathrm{GpsB}$ coiled-coil packs in a parallel manner against an adjacent trimer, but offset such that the N-terminal end of one coiled-coil packs against the $\mathrm{C}$-terminal end of the other (Fig. 4B). This arrangement involves hydrophobic interactions between the highly conserved amino acids F78, L81, and $\mathrm{F} 92$ in BsGpsB, equivalent to F91, L94, and F105 in

FIG. 6. Circular dichroism spectra. (A) Thermal denaturation of Lm GpsB (black line), $\mathrm{N}-L m \mathrm{GpsB}$ (orange line), $\mathrm{C}-L m \mathrm{GpsB}$ (cyan line), and $L m \mathrm{GpsB}_{\mathrm{F} 91 \mathrm{AF} 105 \mathrm{~A}}$ (red line), monitored by circular dichroism; the dashed line represents the summation of the individual thermal melts measured for $\mathrm{N}-L m \mathrm{GpsB}$ and $\mathrm{C}-L m \mathrm{GpsB}$. Unfolding of the secondary structure is observed by monitoring ellipticity at $222 \mathrm{~nm}$. The F91AF105A mutation reduces the stability of $L m \mathrm{GpsB}$. (B) Circular Dichroism spectra of wild-type C-LmGpsB (top) and $\mathrm{C}-L m \mathrm{GpsB}_{\mathrm{F} 105 \mathrm{~A}}$ (bottom panel). The dashed spectrum represents the reconstructed spectra after fitting the secondary structural content with the program CDSStr (30). (C) Thermal denaturation of wt BsGpsB (black line), $B s \mathrm{GpsB}_{\mathrm{T} 75 \mathrm{D}}$ (red line), and $B s \mathrm{GpsB}_{\mathrm{T} 75 \mathrm{E}}$ (cyan line) monitored by circular dichroism ellipticity at $222 \mathrm{~nm}$. The midpoint of the unfolding transition is similar for the three proteins $\left(c .62^{\circ} \mathrm{C}\right)$. 


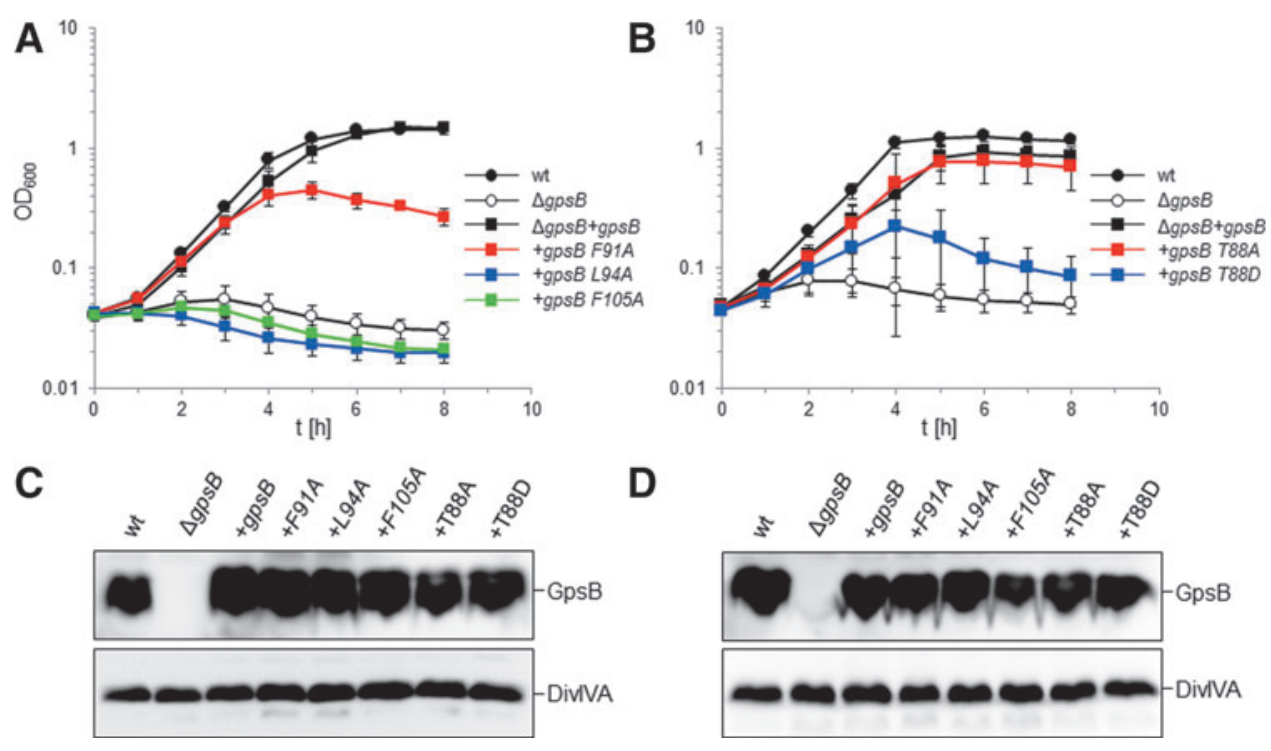

FIG. 7. Effect of mutations in the GpsB C-terminus on growth of L. monocytogenes at $42^{\circ} \mathrm{C}$. (A) L. monocytogenes strains EGD-e (wt), LMJR19 ( $\Delta g p s B)$, LMS56 ( $\Delta g p s B+g p s B)$, LMS185 ( $\Delta g p s B+g p s B F 91 A)$, LMS186 ( $\Delta g p s B+g p s B L 94 A)$, and LMS187 $(\triangle g p s B+g p s B F 105 A)$ were grown in BHI broth containing $1 \mathrm{mM}$ IPTG at $42^{\circ} \mathrm{C}$, and growth was recorded in hourly intervals. (B) Growth of L. monocytogenes strains EGD-e (wt), LMJR19 ( $\Delta$ gpsB), LMS56 ( $\Delta$ gpsB+gpsB), LMJR161 $(\triangle g p s B+g p s B T 88 A)$, and LMJR162 $(\Delta g p s B+g p s B T 88 D)$ was measured as described in $(\mathbf{A})$. All average values and standard deviations were calculated from experiments performed in triplicate. (C) Western blots showing expression of $L m \mathrm{GpsB}$ proteins in the same set of strains as in $(\mathbf{A}, \mathbf{B})$ during growth at $37^{\circ} \mathrm{C}$ (top panel). Cells were harvested for protein isolation at an optical density of $1.0(\lambda=600 \mathrm{~nm})$. A parallel Western blot shows DivIVA expression for control (bottom panel). (D) Stability of $L m \mathrm{GpsB}$ proteins after temperature upshift to $42^{\circ} \mathrm{C}$. Western blot showing amounts of $\mathrm{LmGpsB}$ proteins in cells that were grown at $37^{\circ} \mathrm{C}$ to an optical density of 1.0 and then shifted to $42^{\circ} \mathrm{C}$ for 2 further hours before protein isolation (top panel). Again, a parallel Western blot shows DivIVA protein levels for control (bottom panel).

LmGpsB. From the SEC analysis, F105 is clearly more important for the stability of the hexamer than F91 (Fig. 5A) and this is fully consistent with the complementation assay, in which mutation of F105, as well as L94, has a larger impact than mutation of F91. The milder effect of the F91A mutation may be attributed to the F105A mutation having a greater impact on the concentration of GpsB hexamers in vivo. Overall, these observations support the conclusion that the interactions between $\mathrm{C}-\mathrm{GpsB}$ domains in the GpsB hexamer are similar to those observed in the $\mathrm{C}-\mathrm{Bs} \mathrm{GpsB}$ crystal lattice, which is not predicted to be stable on analysis of the crystal packing with the PDB-PISA web server. However, weak interactions between isolated C-GpsB domains will be stabilized within GpsB by the covalently attached dimeric N-GpsB domains that will bridge two trimers in a hexamer. Such an effect could explain why the fulllength $\mathrm{GpsB}$ protein has a higher $\mathrm{T}_{\mathrm{m}}$ than the combined $\mathrm{CD}$ thermal melts of the isolated domains (Fig. 6A). The stabilizing effect is illustrated schematically in Fig. 4A, in which cyan is used to denote the $\mathrm{N}-L m G \mathrm{GsB}$ dimer that forms a bridge between two C-LmGpsB trimers within the $L m \mathrm{GpsB}$ hexamer. Previous mutagenesis results have demonstrated that the C-terminal domain is essential for formation of GpsB hexamers and that mutations in residues critical for $\mathrm{C}-\mathrm{GpsB}$ trimer formation render $\mathrm{GpsB}$ inactive. ${ }^{11}$ It would therefore appear from the loss of GpsB function in strains harboring gpsB alleles that affect $\mathrm{GpsB}$ hexamer formation that the correct assembly of GpsB is absolutely critical for its function in vivo.

With the arrangement of domains in the SAXS envelope, the distances between covalently linked domains are not equivalent. This asymmetric arrangement requires the linker between domains to adopt different conformations, and indeed secondary structure prediction analyses predict that the linker is disordered. The flexibility and bendability of the linker can be further reconciled with the high frequency of the disorder promoting residues ${ }^{47}$ proline, lysine, methionine serine, and threonine in this region; the 23 amino acid L. monocytogenes GpsB linker has twelve such residues, which are also abundant in the linkers of orthologous GpsB proteins. $^{11}$

The position of F91 and L94 close to or at the interface between subunits is particularly interesting in view of the recent identification that, in B. subtilis, the nearby T75 (equivalent to T88 in L. monocytogenes) is phosphorylated by the kinase $\operatorname{PrkC}^{19}$ and that phosphomimetic mutations at this position produce a gpsB null-like phenotype both in $B$. subtilis and in L. monocytogenes. Similarly, phosphoablative mutations have no demonstrable effect in either species. The straddling of T88 by F91 and L94 suggests that the interaction between GpsB and PrkC will overlap with the interface between $\mathrm{C}-\mathrm{GpsB}$ subunits, and hence, the interaction with PrkC could adjust the arrangement of subunits in the hexamer. The interaction with PrkC could therefore, in turn, influence the interaction with PBP1 by altering the GpsB quaternary structure and the arrangement of PBP1 binding sites. However, the phosphorylation of GpsB, mediated by PrkC, is not in itself sufficient to affect the interaction with PBP1 as both wild-type and phosphomimetic variants of GpsB behaved identically when combined with $B s$ PBP1 in activity assays (Fig. 8). We have shown here and elsewhere $^{11}$ that correct hexamer formation is essential for 


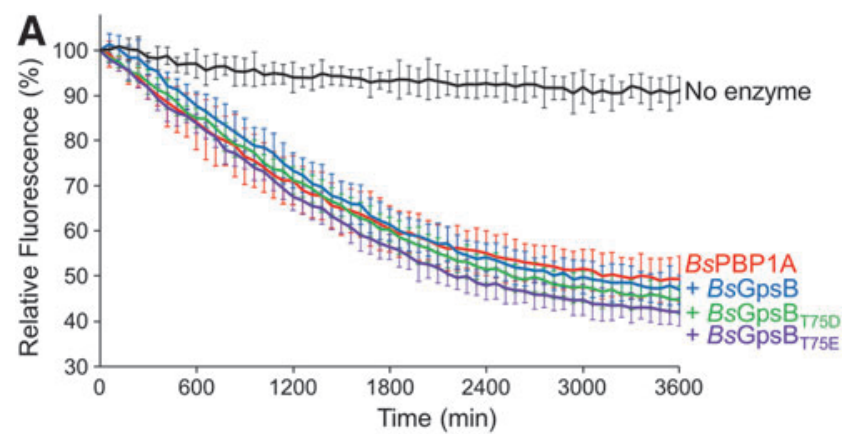

B PBP1A
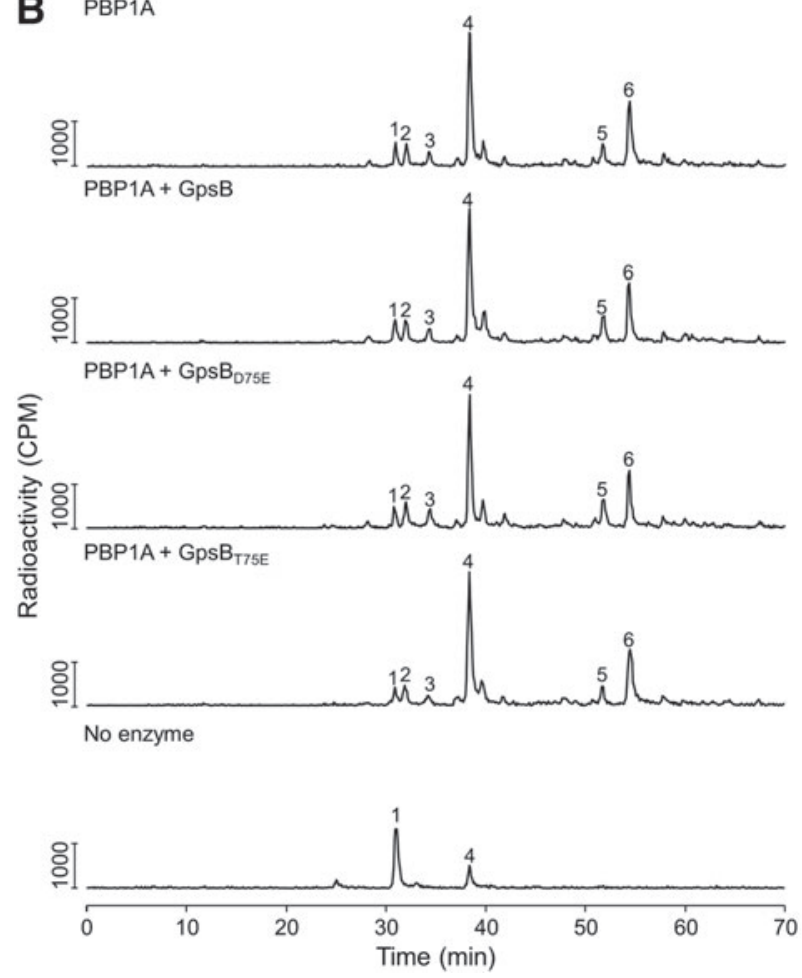

FIG. 8. GpsB does not affect the enzyme activities of PBP1 in vitro. (A) The GTase activity of BsPBP1 in the presence (blue line) and absence of wild-type BsGpsB (red line), Bs $\mathrm{GpsB}_{\mathrm{T} 75 \mathrm{D}}$ (green line), and $B s \mathrm{GpsB}_{\mathrm{T} 75 \mathrm{E}}$ (magenta line) was measured using fluorescently labeled lipid II as described previously. ${ }^{40}$ In the absence of BsPBP1 (black line), no lipid II consumption is observed. Each measurement is shown as the mean $\pm \operatorname{SD}(n=3)$. (B) HPLC chromatograms from in vitro $\mathrm{PG}$ synthesis assays. $B s \mathrm{PBP} 1$ in the presence and absence of $B s G p s B$ was incubated with radiolabeled amidated lipid II-m-DAP. The resultant PG was digested, boiled, and reduced before the resulting muropeptides were separated by HPLC. Peak 1-disaccharide pentapeptide $\left(\mathrm{NH}_{2}\right)$ monophosphate resulting from unused substrate and glycan chain ends; peak 2-disaccharide tetrapeptide $\left(\mathrm{NH}_{2}\right)$ derived from GTase and carboxypeptidase activity; peak 3-disaccharide pentapeptide (nonamidated) from the GTase activity on contaminating nonamidated substrate; peak 4-disaccharide pentapeptide $\left(\mathrm{NH}_{2}\right)$ resulting from the GTase activity; peak 5-bis-disaccharide tetrapeptide $\left(2 \mathrm{NH}_{2}\right)$ resulting from GTase, TPase, and carboxypeptidase activities; peak 6-bis-disaccharide tetrapentapeptide $\left(2 \mathrm{NH}_{2}\right)$ resulting from GTase and TPase activities. HPLC, high-pressure liquid chromatography.
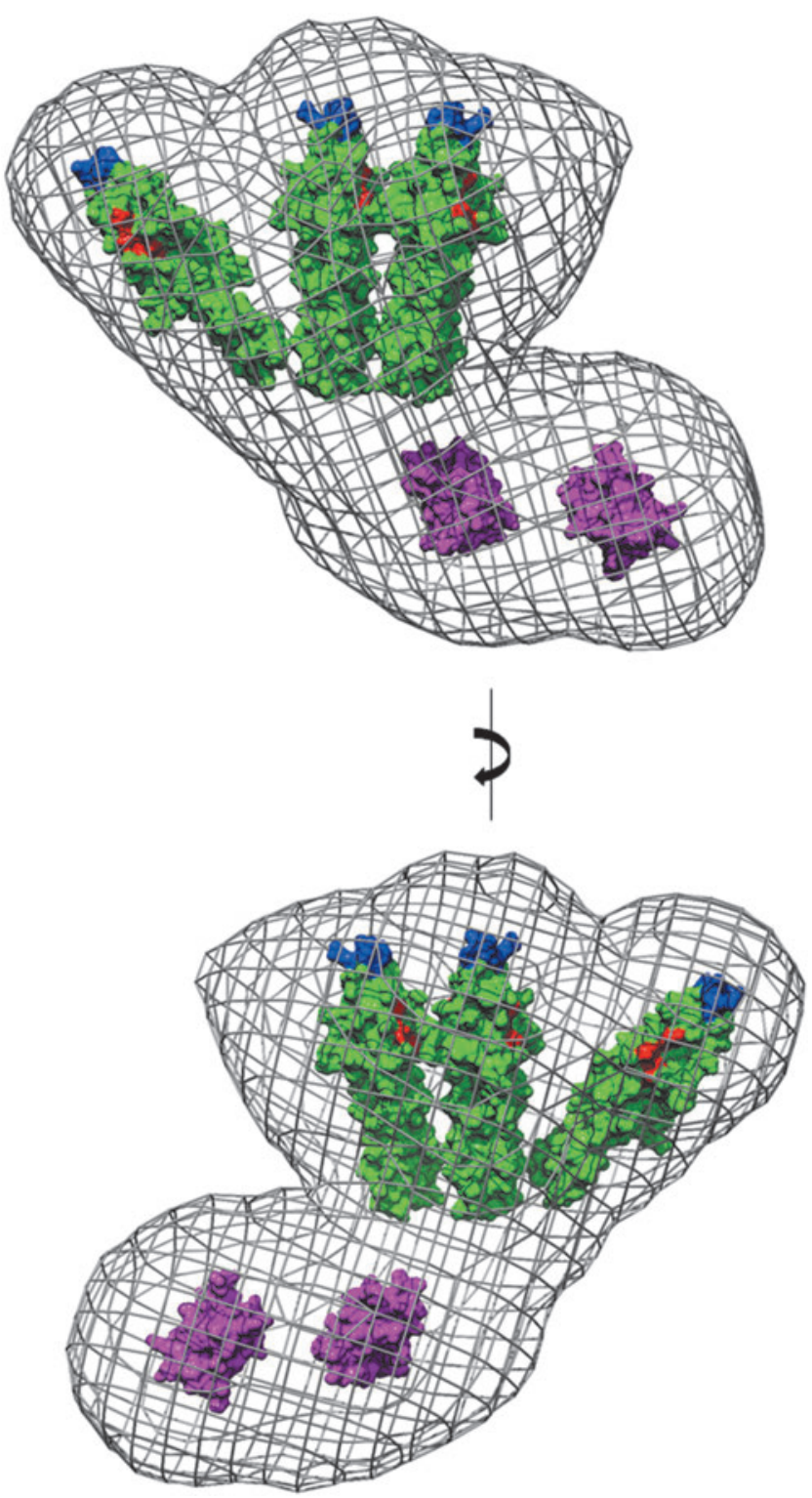

FIG. 9. PBP1 and membrane binding sites in the SAXS model of GpsB. The atomic coordinates of N-GpsB dimers and C-GpsB trimers, represented as molecular surfaces (green and magenta, respectively), have been manually positioned in the averaged $a b$ initio molecular envelope of the $L m \mathrm{GpsB}$ hexamer, shown as a gray mesh. Surface exposed residues critical for the interaction of $L m \mathrm{GpsB}$ with PBP $1^{11}$ are colored red (D33, D37, I40). Residues critical for association of $L m \mathrm{GpsB}$ with the cell membrane ${ }^{11}$ are colored blue (L24, R25). The molecular envelope represented here is the average of 15 independently generated ab initio dummy atom models.

GpsB function in L. monocytogenes, which invites the suggestion that the phosphomimetic mutation instead affects GpsB function by altering its quaternary structure. However, a major effect on GpsB quaternary structure was not evident here as the two phosphomimetic mutants of BsGpsB, T75D and T75E, behaved indistinguishably from wild-type $B s \mathrm{GpsB}$ on SEC and had an identical thermal stability on circular dichroism analysis. Perhaps the gps $B$ null phenotype 
of phosphomimetic mutations reflects the introduction of a net negative charge in this region affecting the ability of GpsB to interact with PrkC or another divisome component. A molecular rationale for the gpsB null phenotype associated with the phosphomimetic mutation reported earlier ${ }^{19}$ and herein remains to be determined.

An important functional consequence of a closed tripodlike arrangement, as opposed to a more open "splayed out" arrangement of subunits, is the potential for the GpsB hexamer to interact simultaneously with multiple membraneembedded PBP1 molecules. In the SAXS model of GpsB, the binding sites for PBP1 (a surface cleft in the $\mathrm{N}$-terminal domain $^{11}$ ) are clustered at one end of the elongated hexamer (Fig. 9). Similarly, the residues critical for the association of GpsB with the cell membrane (L24 and R25 in $L m \mathrm{GpsB}^{11}$ ) are also clustered at the same end of the hexamer (Fig. 9). $\mathrm{GpsB}$, therefore, has the implicit capacity to interact with multiple PBP1 molecules and thus to impact upon the arrangement of PBP1 molecules in the divisome, and this capacity may explain phenotypic and genetic evidence that GpsB regulates cell wall synthesis. ${ }^{5,11}$ In $E$. coli, the essential cell division protein FtsN, which is unrelated to GpsB, may play a similar role as it stabilizes dimeric or multimeric forms of PBP1B in vitro. ${ }^{48}$

At $37^{\circ} \mathrm{C}$, the $\Delta g p s B$ null mutant makes the overexpression of PBP1 lethal in L. monocytogenes, ${ }^{11}$ which suggests that $\mathrm{GpsB}$ acts as a negative regulator of at least one of the enzymatic activities of PBP1. A simple regulatory mechanism could entail GpsB promoting the oligomerization of PBP1, a feasible scenario given that the GpsB hexamer has the potential to interact with multiple PBP1 molecules. PBP1B from E. coli forms dimers, and dimerization enhances both GTase and TPase activities in vitro. ${ }^{41}$ The activities of $E$. coli $\mathrm{PBP} 1 \mathrm{~B}$ are stimulated or modulated by interactions with $\mathrm{LpoB}, \mathrm{FtsN}$, TolA, and CpoB, and these interactions are essential for the function of this peptidoglycan synthase in the cell. ${ }^{39,48-53}$ However, there was no effect of $B s \mathrm{GpsB}$ on either the GTase or the TPase activity of PBP1 in vitro (Fig. 8), which would argue against a regulatory mechanism. Any modulation of PBP1 activity by GpsB in vivo must therefore require other divisome components and/or membrane-bound elements that are not recapitulated in these experiments in vitro. In particular, simply by controlling the spatial arrangement of PBP1 molecules in the membrane in vivo, GpsB may influence both the arrangement of peptidoglycan strands and the pattern of intrastrand cross-links in the cell wall.

In this regard, the hexameric GpsB, and its flexible nature, could potentiate PBP1 activity or cellular localization by changes to the quaternary structure of GpsB: movements of the GpsB domains relative to one another could translate to large changes in the spatial arrangement of PBP1 binding sites. GpsB might thus act as an allosteric sensor, with its interaction with PBP1 modulated by changes in quaternary structure induced by interactions with other purported binding partners such as PrkC, EzrA, MreC, or DivIVA. These ideas will form the focus of our future experiments.

\section{Acknowledgments}

The authors thank Dr. Stephen Prince at the University of Manchester for advice on planning SAXS experiments.
They thank Dr. Owen Davies at the University of Newcastle for SEC-MALS analysis. They would also like to thank PETRAIII and Diamond Light Source for beamtime on beamlines P12 and B21, respectively, and Drs. Cy Jefferies and Mark Tully for assistance during SAXS data collection. They thank Peter Sharratt at the Peptide and Nucleic Acid Facility, Cambridge University, for amino acid analysis. The research leading to these results has received funding from the European Community's Seventh Framework Programme (FP7/2007-2013) under BioStruct-X (grant agreement \#283570 to CB for SAXS beamtime), the UK Biotechnology and Biological Sciences Research Council (BB/ M001180/1 to RJL), the Wellcome Trust (101824/Z/13/Z to WV), and the German Research Foundation (HA 6830/1-1 to $\mathrm{SH})$.

\section{Disclosure Statement}

No competing financial interests exist.

\section{References}

1. den Blaauwen, T., J.M. Anreu, and O. Monasterio. 2014. Bacterial cell division proteins as antibiotic targets. Bioorg. Chem. 55:27-38.

2. Gamba, P., J. Veening, N. Saunders, L. Hamoen, and R. Daniel. 2009. Two-step assembly dynamics of the Bacillus subtilis divisome. J. Bacteriol. 191:4186-4194.

3. Osawa, M., D.E. Anderson, and H.P. Erickson. 2008. Reconstitution of contractile FtsZ rings in liposomes. Science 320:792-794.

4. Typas, A., M. Banzhaf, C.A. Gross, and W. Vollmer. 2012. From the regulation of peptidoglycan synthesis to bacterial growth and morphology. Nat. Rev. Microbiol. 10:123-136.

5. Claessen, D., R. Emmins, L. Hamoen, R. Daniel, J. Errington, and D. Edwards. 2008. Control of the cell elongationdivision cycle by shuttling of PBP1 protein in Bacillus subtilis. Mol. Microbiol. 68:1029-1046.

6. Cleverley, R.M., J.R. Barrett, A. Baslé, N.K. Bui, L. Hewitt, A. Solovyova, Z.Q. Xu, R.A. Daniel, N.E. Dixon, E.J. Harry, A.J. Oakley, W Vollmer, and RJ Lewis. 2014. Structure and function of a spectrin-like regulator of bacterial cytokinesis. Nat. Commun. 5:5421.

7. Singh, J.K., R.D. Makde, V. Kumar, and D. Panda. 2007. A membrane protein, EzrA, regulates assembly dynamics of FtsZ by interacting with the C-terminal tail of FtsZ. Biochemistry 46:11013-11022.

8. Steele, V.R., A.L. Bottomley, J. Garcia-Lara, J. Kasturiarachchi, and S.J. Foster. 2011. Multiple essential roles for EzrA in cell division of Staphylococcus aureus. Mol. Microbiol. 80:542-555.

9. Jorge, A.M., E. Hoiczyk, J.P. Gomes, and M.G. Pinho. 2011. EzrA contributes to the regulation of cell size in Staphylococcus aureus. PLoS One 6:e27542.

10. Pedersen, L.B., E.R. Angert, and P. Setlow. 1999. Septal localization of penicillin-binding protein 1 in Bacillus subtilis. J. Bacteriol. 181:3201.

11. Rismondo, J., R.M. Cleverley, H.V. Lane, S. Großhennig, A. Steglich, L. Möller, G.K. Mannala, T. Hain, R.J. Lewis, and S. Halbedel. 2016. Structure of the bacterial cell division determinant GpsB and its interaction with penicillin binding proteins. Mol. Microbiol. 99:978-998.

12. Considine, K.M., R.D. Sleator, A.L. Kelly, G.F. Fitzgerald, and C. Hill. 2011. Identification and characterization of an 
essential gene in Listeria monocytogenes using an inducible gene expression system. Bioeng. Bugs 2:150-159.

13. Song, J.H., K.S. Ko, J.Y. Lee, J.Y. Baek, W.S. Oh, H.S. Yoon, J.Y. Jeong, and J. Chun. 2005. Identification of essential genes in Streptococcus pneumoniae by allelic replacement mutagenesis. Mol. Cells 19:365-374.

14. Massidda, O., L. Nováková, and W. Vollmer. 2013. From models to pathogens: how much have we learned about Streptococcus pneumoniae cell division? Environ. Microbiol. 15:3133-3157.

15. Pinho, M.G., M. Kjos, and J.W. Veening. 2013. How to get (a)round: mechanisms controlling growth and division of coccoid bacteria. Nat. Rev. Microbiol. 11:601-614.

16. Land, A.D., H.C. Tsui, O. Kocaoglu, S.A. Vella, S.L. Shaw, S.K. Keen, L.T. Sham, E.E. Carlson, and M.E. Winkler. 2013. Requirement of essential Pbp2x and GpsB for septal ring closure in Streptococcus pneumoniae D39. Mol. Microbiol. 90:939-955.

17. Thanassi, J.A., S.L. Hartman-Neumann, T.J. Dougherty, B.A. Dougherty, and M.J. Pucci. 2002. Identification of 113 conserved essential genes using a high-throughput gene disruption system in Streptococcus pneumoniae. Nucl. Acids Res. 30:3152-3162.

18. Fleurie, A., S. Manuse, C. Zhao, N. Campo, C. Cluzel, J.P. Lavergne, C. Freton, C. Combet, S. Guiral, B. Soufi, B. Macek, E. Kuru, M.S. VanNieuwenhze, Y.V. Brun, A.M. Di Guilmi, J.P. Claverys, A. Galinier, and C. Grangeasse. (2014). Interplay of the serine/threoninekinase StkP and the paralogs DivIVA and GpsB in pneumococcal cell elongation and division. PLoS Genet. 10:e1004275.

19. Pompeo, F., E. Foulquier, B. Serrano, C. Grangeasse, and A. Galinier. 2015. Phosphorylation of the cell division protein GpsB regulates PrkC kinase activity through a negative feedback loop in Bacillus subtilis. Mol. Microbiol. 97:139-150.

20. Yeats, C., R.D. Finn, and A. Bateman. 2002. The PASTA domain: a beta-lactam-binding domain. Trends Biochem. Sci. 27:438.

21. Shah, I.M., M.H. Laaberki, D.L. Popham, and J. Dworkin. 2008. A eukaryotic-like Ser/Thr kinase signals bacteria to exit dormancy in response to peptidoglycan fragments. Cell 135:486-496.

22. Lenarcic, R., S. Halbedel, L. Visser, M. Shaw, L.J. Wu, J. Errington, D. Marenduzzo, and L.W. Hamoen. 2009. Localisation of DivIVA by targeting to negatively curved membranes. EMBO J. 28:2272-2282.

23. Yun, R.H., A. Anderson, and J. Hermans. 1991. Proline in alpha-helix: stability and conformation studied by dynamics simulation. Proteins 10:219-228.

24. Sambrook, J., E.F. Fritsch, and T. Maniatis. 1989. Molecular Cloning: A Laboratory Manual. 2nd ed. Cold Spring Harbor Laboratory Press, Cold Spring Harbor, NY.

25. Zheng, L., U. Baumann, and J.L. Reymond. 2004. An efficient one-step site-directed and site-saturation mutagenesis protocol. Nucl. Acids Res. 32:e115.

26. Monk, I.R., C.G. Gahan, and C. Hill. 2008. Tools for functional postgenomic analysis of Listeria monocytogenes. Appl. Environ. Microbiol. 74:3921-3934.

27. Thomaides, H.B., M. Freeman, M. El Karoui, and J. Errington. 2001. Division site selection protein DivIVA of Bacillus subtilis has a second distinct function in chromosome segregation during sporulation. Genes Dev. 15:16621673.
28. Peränen, J., M. Rikkonen, M. Hyvönen, and L. Kääriäinen. 1996. T7 vectors with modified T7lac promoter for expression of proteins in Escherichia coli. Anal. Biochem. 236:371-373.

29. Gill, S.C., and P.H. von Hippel. 1989. Calculation of protein extinction coefficients from amino acid sequence data. Anal. Biochem. 182:319-326.

30. Sreerama, N., and R.W. Woody. 2000. Estimation of protein secondary structure from CD spectra: Comparison of CONTIN, SELCON and CDSSTR methods with an expanded reference set. Anal. Biochem. 287:252-260.

31. Whitmore, L., and B.A. Wallace. 2008. Protein secondary structure analyses from circular dichroism spectroscopy: methods and reference databases. Biopolymers 89:392-400.

32. Round, A.R., D. Franke, S. Moritz, R. Huchler, M. Fritsche, D. Malthan, R. Klaering, D.I. Svergun, and M. Roessle. 2008. Automated sample-changing robot for solution scattering experiments at the EMBL Hamburg SAXS station X33. J. Appl. Cryst. 41:913-917.

33. Franke, D., A.G. Kikhney, and D.I. Svergun. 2012. Automated acquisition and analysis of small angle X-ray scattering data. Nucl. Instrum. Methods Phys. Res. A689:52-59.

34. Svergun, D.I. 1992. Determination of the regularization parameter in indirect-transform methods using perceptual criteria. J. Appl. Cryst. 25:495-503.

35. Volkov, V.V., and D.I. Svergun. 2003. Uniqueness of ab initio shape determination in small-angle scattering J. Appl. Cryst. 36:860-864.

36. Pettersen, E., T. Goddard, C. Huang, G. Couch, D. Greenblatt, E. Meng, and T. Ferrin. 2004. UCSF Chimera-a visualization system for exploratory research and analysis. J. Comp. Chem. 25:1605-1612.

37. Rambo, R.P., and J.A. Tainer. 2013. Accurate assessment of mass, models and resolution by small-angle scattering. Nature 496:477-481.

38. Breukink, E., H.E. van Heusden, P.J. Vollmerhaus, E. Swiezewska, L. Brunner, S. Walker, A.J. Heck, and B. de Kruijff. 2003. Lipid II is an intrinsic component of the pore induced by nisin in bacterial membranes. J. Biol. Chem. 278:19898-19903.

39. Egan, A.J., J. Biboy, I. van't Veer, E. Breukink, and W. Vollmer. 2015. Activities and regulation of peptidoglycan synthases. Phil. trans. R. Soc. Lond. B Biol. Sci. 370: 20150031.

40. Banzhaf, M., B. van den Berg van Saparoea, M. Terrak, C. Fraipont, A. Egan, J. Philippe, A. Zapun, E. Breukink, M. Nguyen-Distèche, T. den Blaauwen, and W. Vollmer. 2012. Cooperativity of peptidoglycan synthases active in bacterial cell elongation. Mol. Microbiol. 85:179-194.

41. Bertsche, U., E. Breukink, T. Kast, and W. Vollmer. 2005. In vitro murein (peptidoglycan) synthesis by dimers of the bifunctional transglycosylase-transpeptidase PBP1B from Escherichia coli. J. Biol. Chem. 280:38096-38101.

42. Svergun, D.I., C. Barberato, and M.H.J. Koch. 1995. CRYSOL-a program to evaluate X-ray solution scattering of biological macromolecules from atomic coordinates. J. Appl. Cryst. 28:768-773.

43. Svergun, D.I. 1999. Restoring low resolution structure of biological macromolecules from solution scattering using simulated annealing. Biophys. J. 76:2879-2886.

44. Rambo, R.P., and J.A. Tainer. 2011. Characterizing flexible and intrinsically unstructured biological macromolecules by SAS using the Porod-Debye law. Biopolymers 95:559571 . 
45. Koch, M.H., P. Vachette, and D.I. Svergun. 2003. Smallangle scattering: a view on the properties, structures and structural changes of biological macromolecules in solution. Quart. Rev. Biophys. 36:147-227.

46. Lebar, M.D., J.M. May, A.J. Meeske, S.A. Leiman, T.J. Lupoli, H. Tsukamoto, R. Losick, D.Z. Rudner, S. Walker, and D. Kahne. 2014. Reconstitution of peptidoglycan crosslinking leads to improved fluorescent probes of cell wall synthesis. J. Am. Chem. Soc. 136:10874-10877.

47. Linding, R., L. Jensen, F. Diella, P. Bork, T. Gibson, and R. Russell. 2003. Protein disorder prediction: implications for structural proteomics. Structure 11:1453-1459.

48. Müller, P., C. Ewers, U. Bertsche, M. Anstett, T. Kallis, E. Breukink, C. Fraipont, M. Terrak, M. Nguyen-Distèche, and W. Vollmer. 2007. The essential cell division protein FtsN interacts with the murein (peptidoglycan) synthase PBP1B in Escherichia coli. J. Biol. Chem. 282:3639436402.

49. Typas, A., M. Banzhaf, B. van den Berg van Saparoea, J. Verheul, J. Biboy, R.J. Nichols, M. Zietek, K. Beilharz, K. Kannenberg, M. von Rechenberg, E. Breukink, T. den Blaauwen, C.A. Gross, and W. Vollmer. 2010. Regulation of peptidoglycan synthesis by outer-membrane proteins. Cell 143:1097-1109.

50. Egan, A.J., N.L. Jean, A. Koumoutsi, C.M. Bougault, J. Biboy, J. Sassine, A.S. Solovyova, E. Breukink, A. Typas, W. Vollmer, and J.P. Simorre. 2014. Outer-membrane lipoprotein LpoB spans the periplasm to stimulate the peptidoglycan synthase PBP1B. Proc. Natl. Acad. Sci. USA. 111:8197-8202.

51. Gray, A.N., A.J. Egan, I.L. Van't Veer, J. Verheul, A. Colavin, A. Koumoutsi, J. Biboy, A.F. Altelaar, M.J. Damen, K.C. Huang, J.P. Simorre, E. Breukink, T. den Blaauwen, A. Typas, C.A. Gross, and W. Vollmer. 2015.
Coordination of peptidoglycan synthesis and outer membrane constriction during Escherichia coli cell division. Elife 4:e07118.

52. Paradis-Bleau, C., M. Markovski, T. Uehara, T.J. Lupoli, S. Walker, D.E. Kahne, and T.G. Bernhardt. 2010. Lipoprotein cofactors located in the outer membrane activate bacterial cell wall polymerases. Cell 143:1110-1120.

53. Lupoli, T.J., M.D. Lebar, M. Markovski, T. Bernhardt, D. Kahne, and S. Walker. 2014. Lipoprotein activators stimulate Escherichia coli penicillin-binding proteins by different mechanisms. J. Am. Chem. Soc. 136:52-55.

54. Glaser, P., L. Frangeul, C. Buchrieser, C. Rusniok, A. Amend, F. Baquero, P. Berche, H. Bloecker, P. Brandt, T. Chakraborty, A. Charbit, F. Chetouani, E. Couve, A. de Daruvar, P. Dehoux, E. Domann, G. Dominguez-Bernal, E. Duchaud, L. Durant, O. Dussurget, K.D. Entian, H. Fsihi, F. Garcia-del Portillo, P. Garrido, L. Gautier, W. Goebel, N. Gomez-Lopez, T. Hain, J. Hauf, D. Jackson, L.M. Jones, U. Kaerst, J. Kreft, M. Kuhn, F. Kunst, G. Kurapkat, E. Madueno, A. Maitournam, J.M. Vicente, E. Ng, H. Nedjari, G. Nordsiek, S. Novella, B. de Pablos, J.C. Perez-Diaz, R. Purcell, B. Remmel, M. Rose, T. Schlueter, N. Simoes, A. Tierrez, J.A.Vazquez-Boland, H. Voss, J. Wehland, and P. Cossart. 2001. Comparative genomics of Listeria species. Science 294:849-852.

Address correspondence to: Richard J. Lewis, MA, DPhil Institute for Cell and Molecular Biosciences University of Newcastle Newcastle upon Tyne NE2 $4 \mathrm{HH}$ United Kingdom

E-mail: r.lewis@ncl.ac.uk 